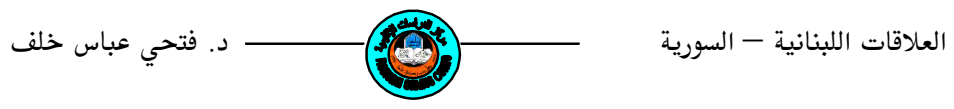

العلاقات اللبنانية - السورية 1961 - 1964

مدرس / قسم التاريخ- كلية التربية / جامعة الموصل فلف عباس ملف

مستخلص البحث

يتركز موضوع البحث حول مرحلة مهمة من تاريخ لبنان وسوريا خـلال المـدة (1961-1964)، أي

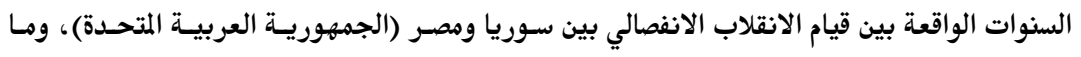

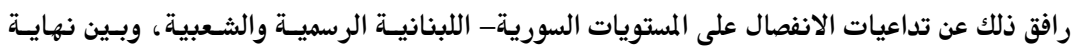

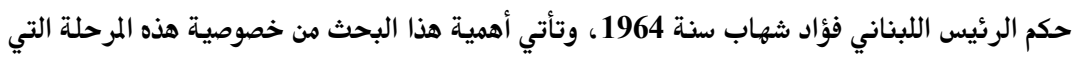

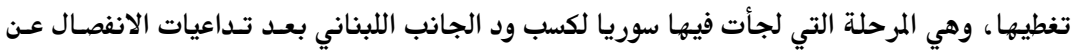
مصر واتخاذها خطر مجابهة التيار الناصري في البلدان العربية.

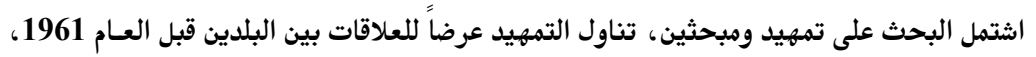

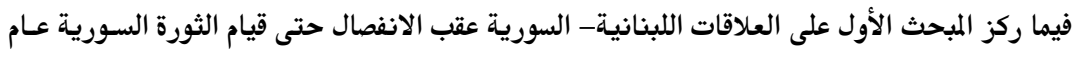

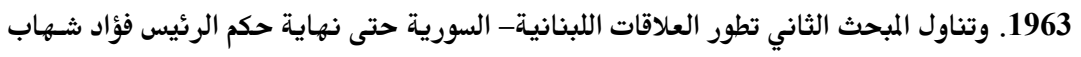

منذ أواسط الخمسينيات أخذت العلاقات اللبنانية - السورية تزداد تـدهورا بعد وقوف

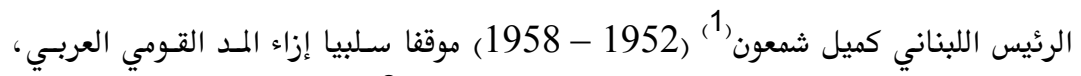

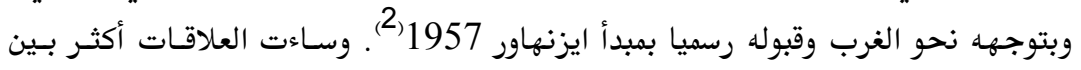

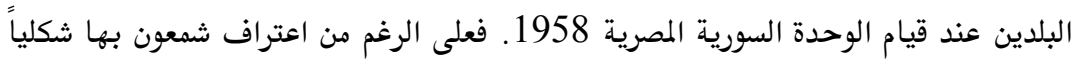

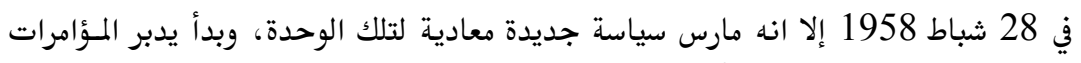
ويشن حملات إعلامية ضدها (3). 
بعد تولي اللواء فؤاد شهاب(4) مذصب رئاسـة الجمهوريسة اللبنانيـة في 31 تمـوز 1958

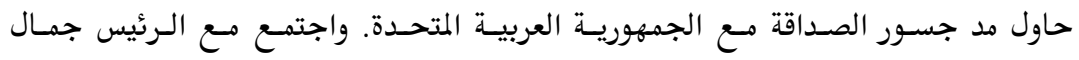

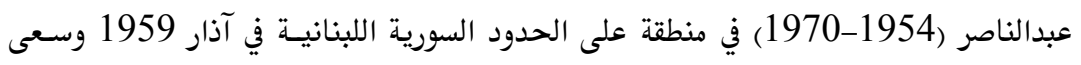

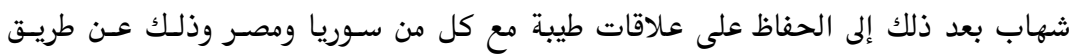
إتباعه سياسة خارجية لا تتعارض مع سياستيهما (5).

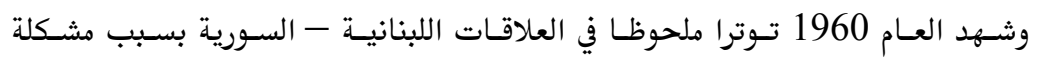

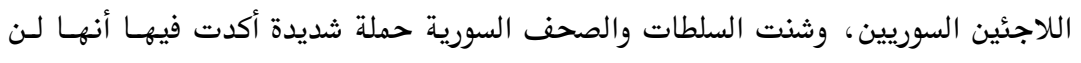

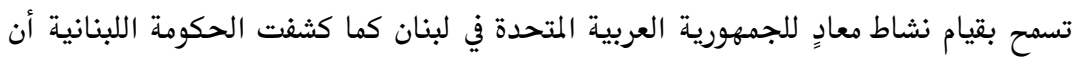

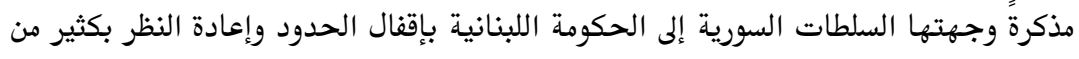

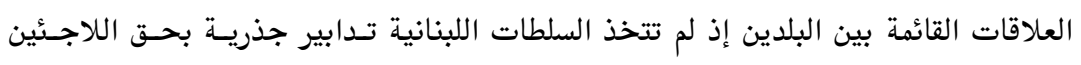

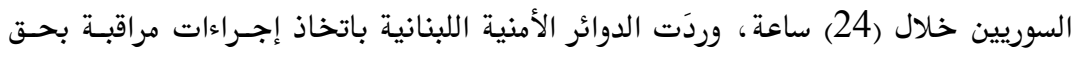

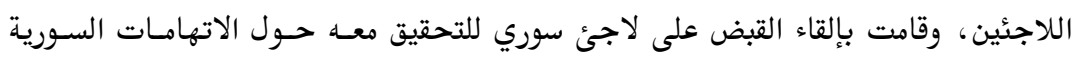

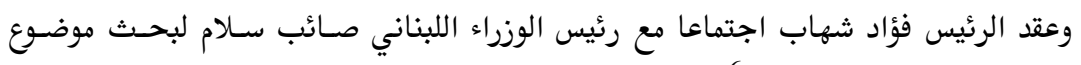
اللاجئين السوريين إلى لبنان (6). استمرت السلطات اللبنانية في إظهار اهتمامها بالاتهامات السورية فقاهـت في 2 تشـرين

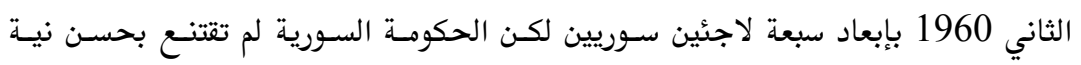
الحكومة اللبنانية نتيجة التدابير المتخذة(7).

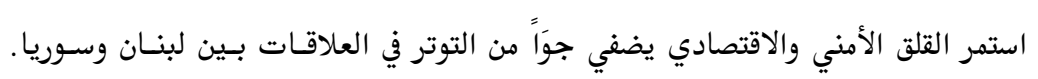

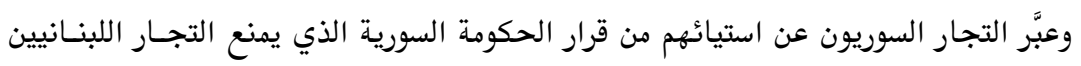

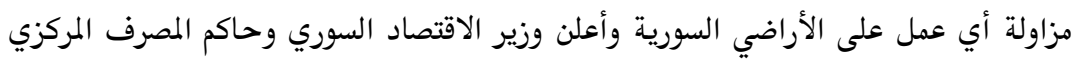

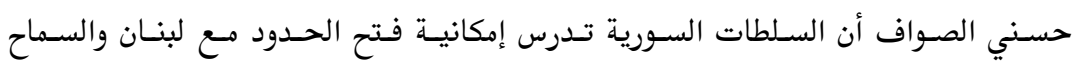

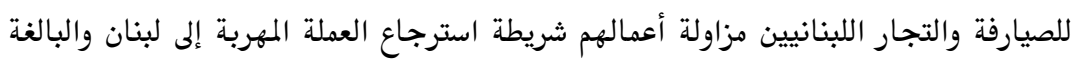

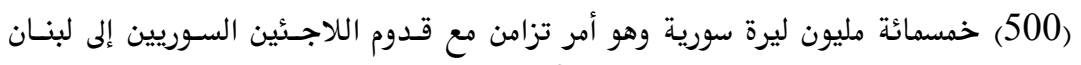

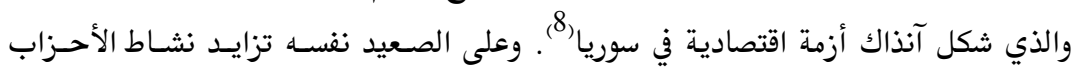


اللبنانية المناوئة للجمهورية العربية المتحدة، وفي 25 شباط 1961 ألقى الرئيس عبد الناصر

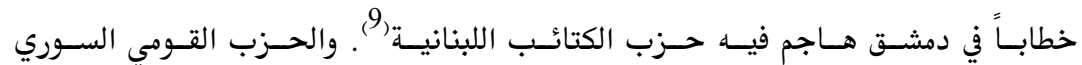

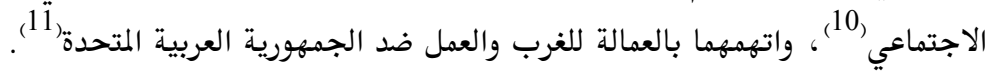

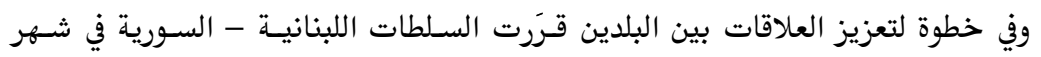

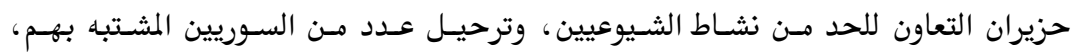

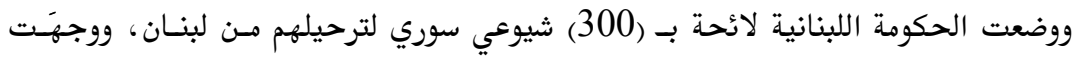

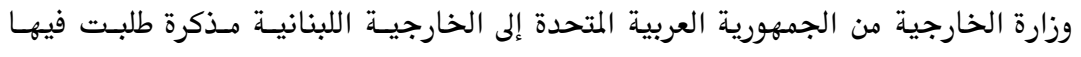

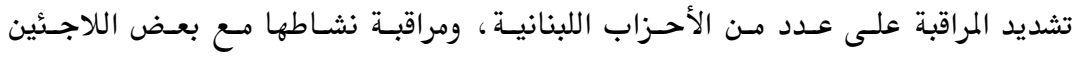

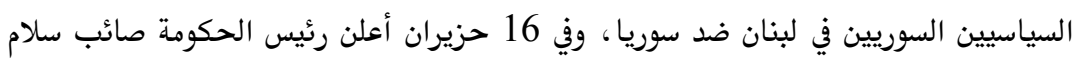

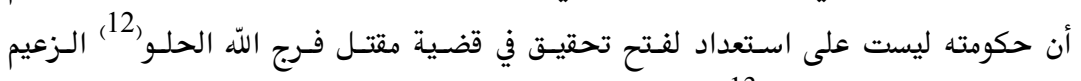
الشيوعي اللبناني في دمشق (13).

العلاقات بين البلدين حتى عام 1963 - اثر الانقلاب الانفصالي على العلاقات اللبنانية - السورية العاتئ

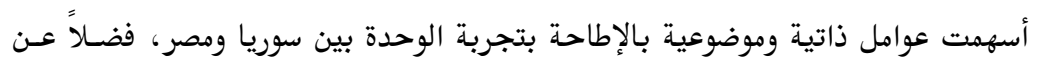

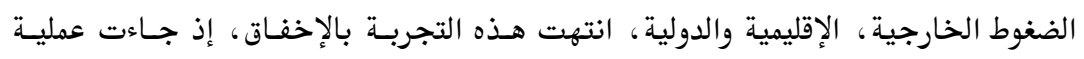

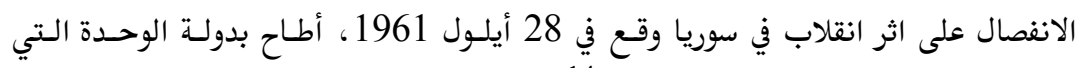

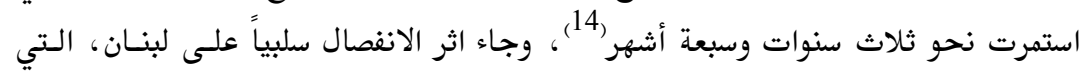

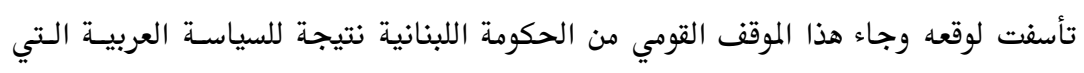

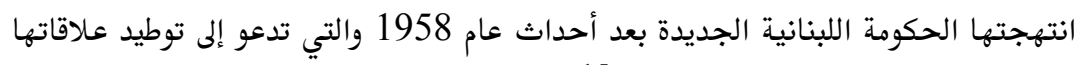
مع سوريا والسير ضمن سياستها العربية(15).

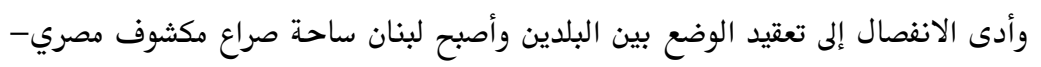

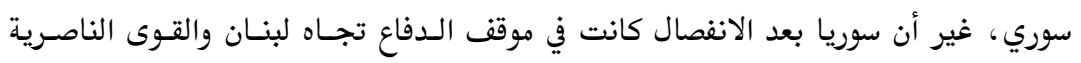




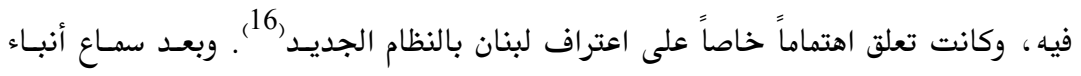

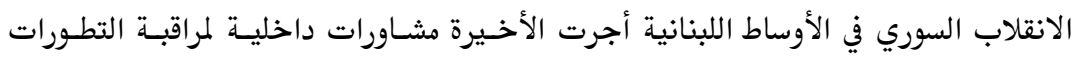

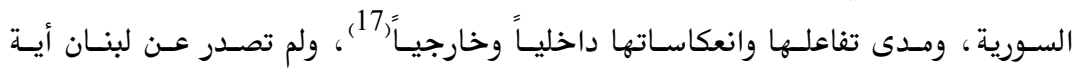
تصريحات تؤيد الانفصال بل على العكس فقد قام لبنان باحتضان المصريين الذين تم طردهم

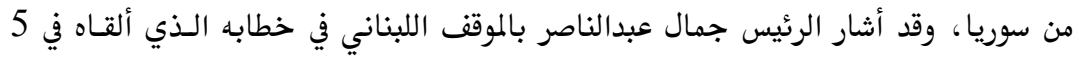

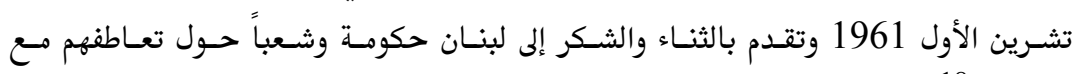

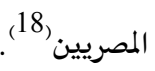

وفي يوم 30 أيلول 1961 خرجت تظاهرات شعبية في مدن : بيروت وطرابلس، وصيدا

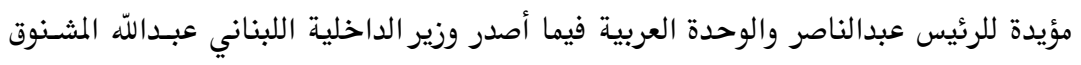

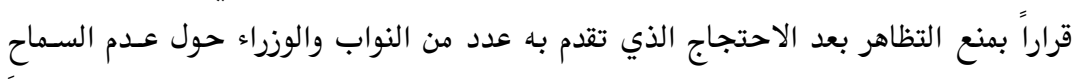

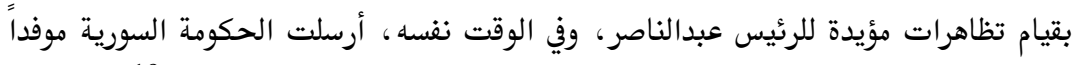

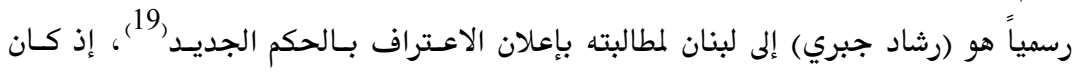

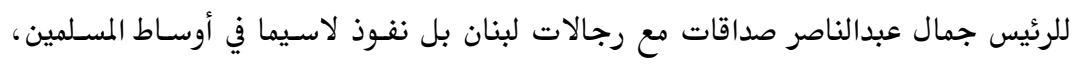

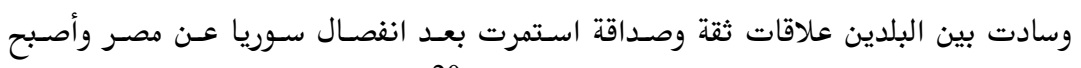

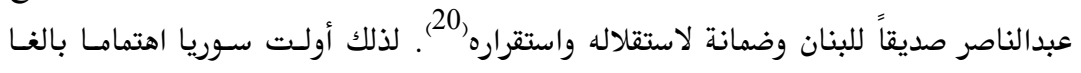

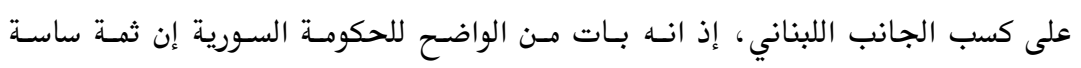

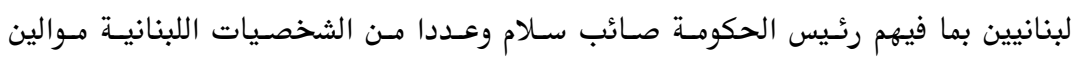

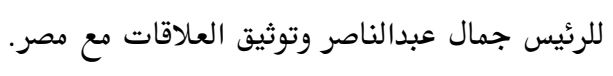

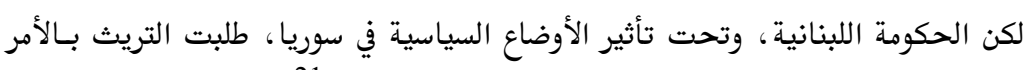

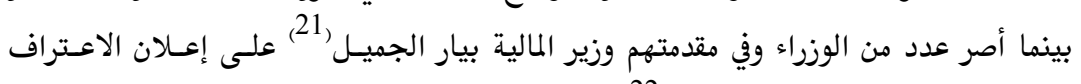

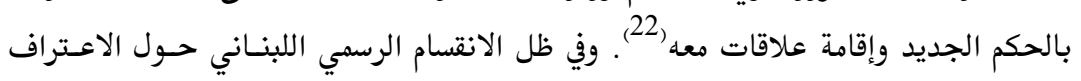

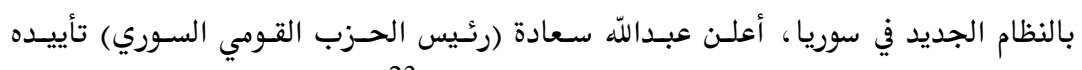
للمشروع السوري القاضي بإقامة اتحاد بين الدول العربية(23). 
وعلى الصعيد نغسه اصدر الحزب التقدمي الاشتراكي (24) في 4 تشرين الأول 1961 بيانا

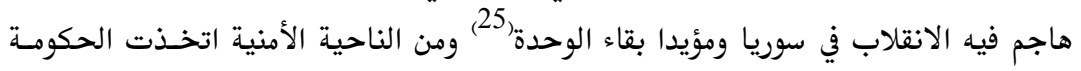

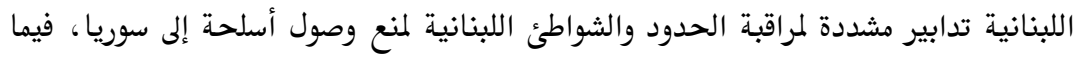

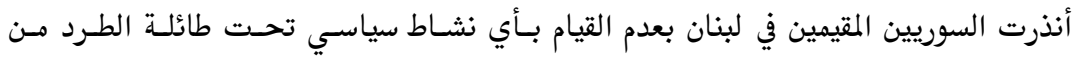

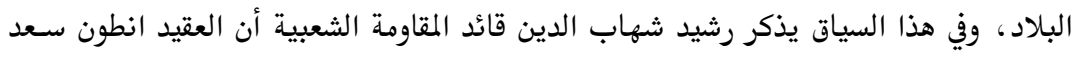

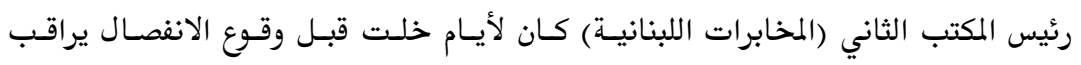

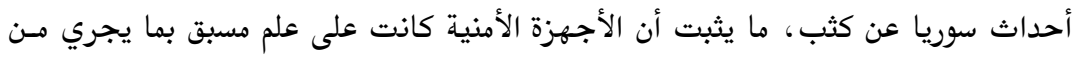

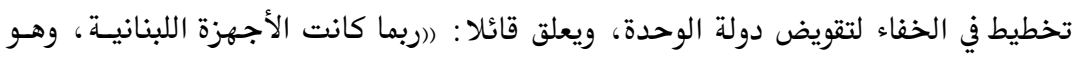

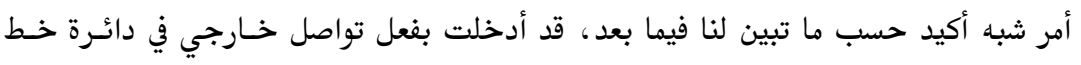

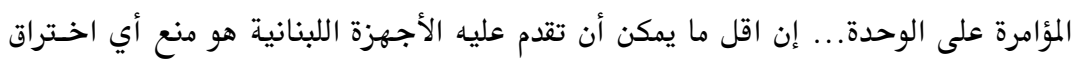

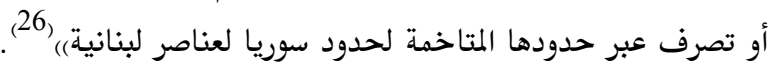

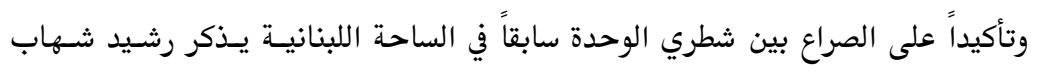

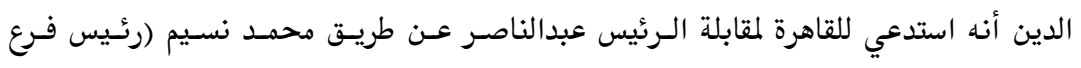

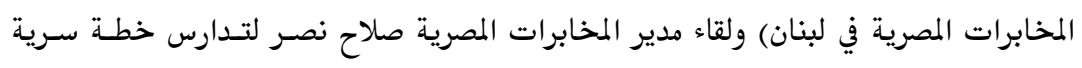

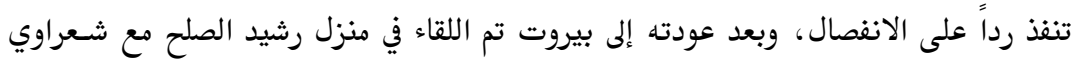

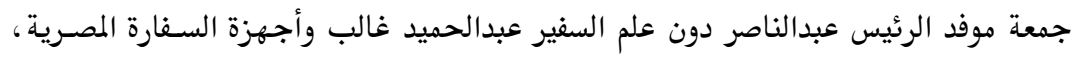

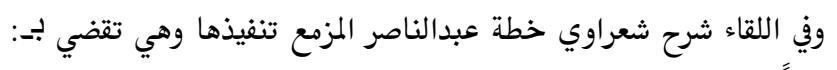

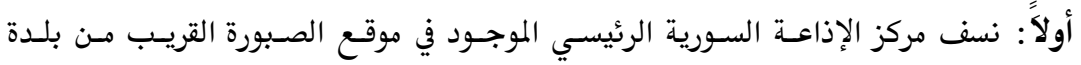

$$
\text { ميسلون السورية ومن قرية (دير العشائر) اللبنانية. }
$$

ثانياً: إنزال مشاة من البحرية المصرية مع فرقة من المظليين في مدينة اللاذقية.

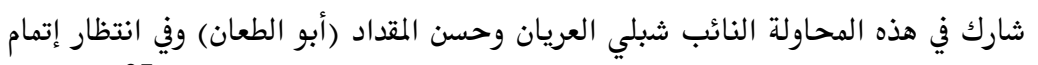

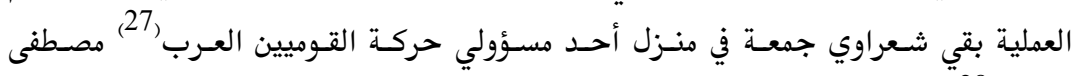

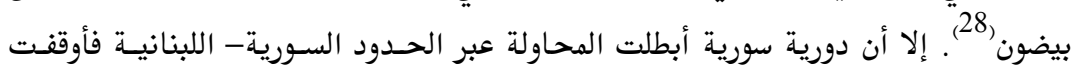

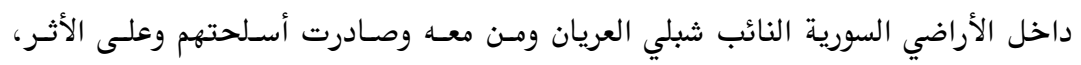


قامـت الحكومسة اللبنانيـة بـاجراء اتصـالات مـع الحكومسة السـورية أدت إلى إطـلاق سـراح الموقوفين (29).

في 5 تشرين الأول اصدر مجلس الوزراء اللبناني بيانا استنكر فيه الأحداث التي وصفها

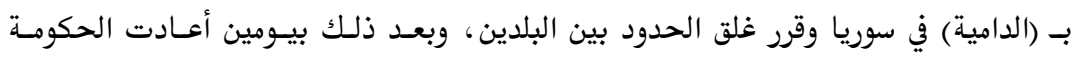

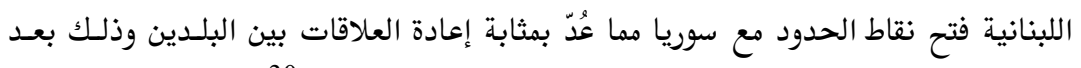

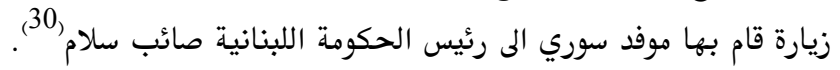

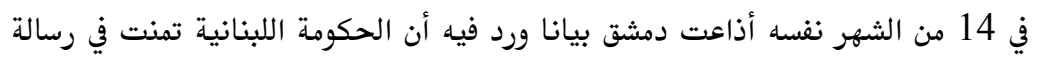

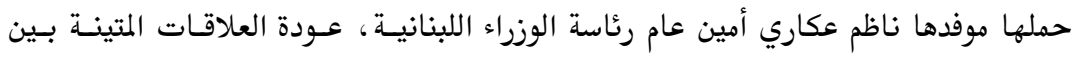

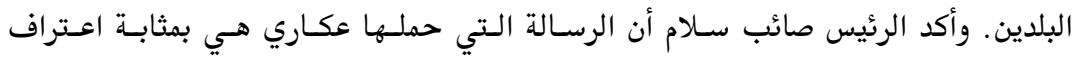

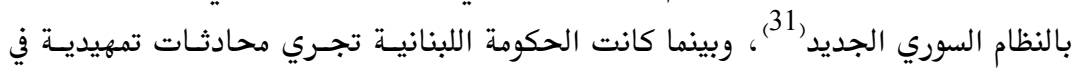

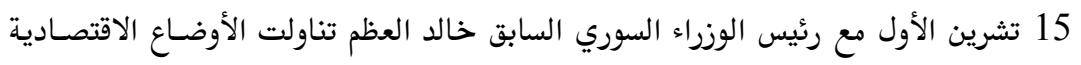

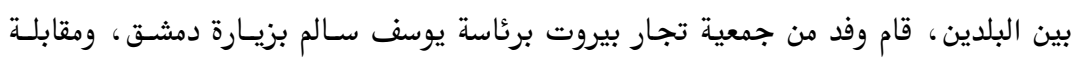

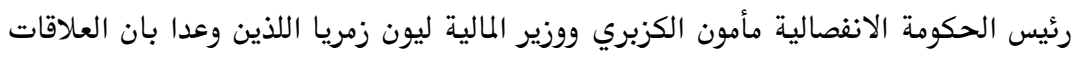

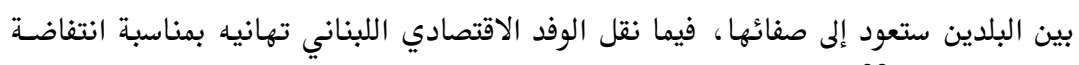

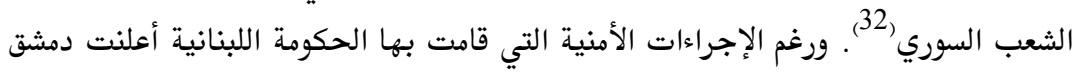

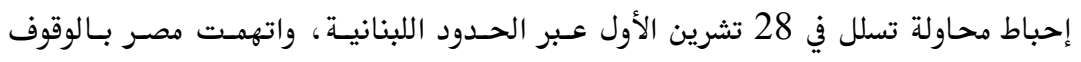

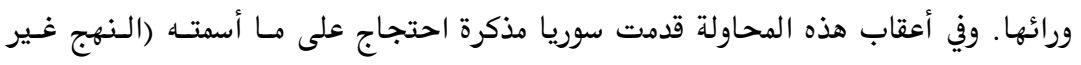

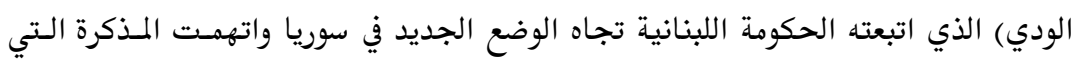

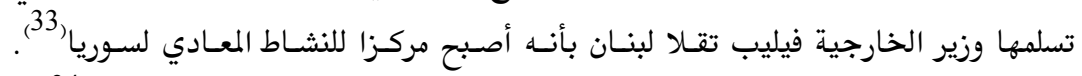

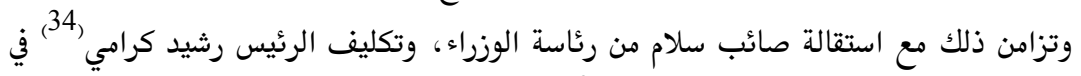

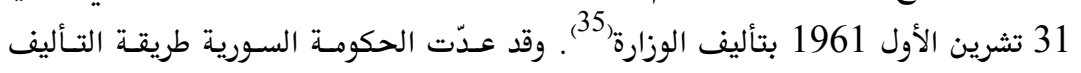

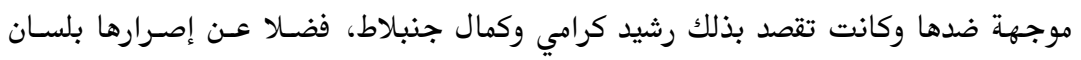

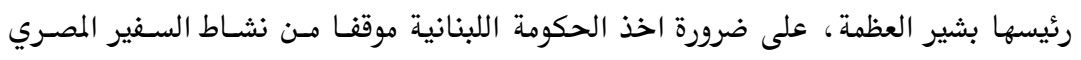
عبدالحميد غالب، وإقامة تمثيل سياسي يتضمن تحقيق المصالح المشتركة ويحفظ امن سوريا، 
وكان تركيز المسؤولين السوريين في هذه المرحلة على الجانب الأمني، لاسيما بعد اتهام سوريا

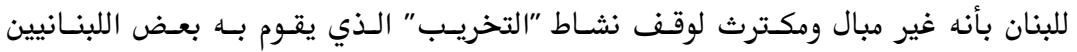
باجتياز الحدود إلى سوريا، والدعوة إلى قطع الاتصالات معه لأنسه لا يلتـزم (لبنـان) سياسـة لئس الحياد (36).

غير أن الحكومة اللبنانية وبلسان وزير داخليتها كمـال جنسبلاط373 نفـت وجـود نشـاط

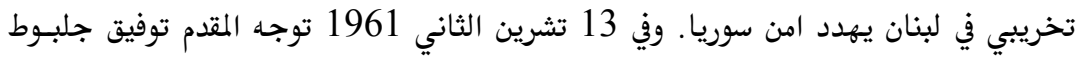

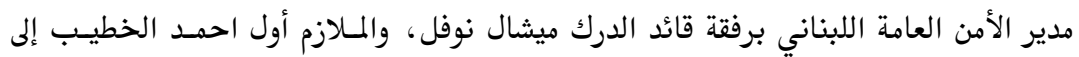
سوريا للتباحث مع المسؤولين السوريين في الشؤون الأمنية بين البلدين (38).

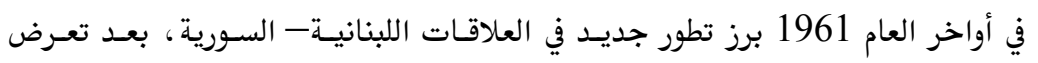

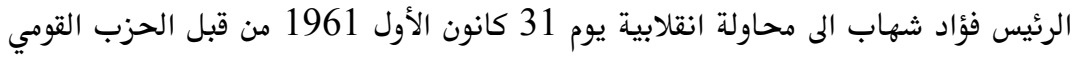

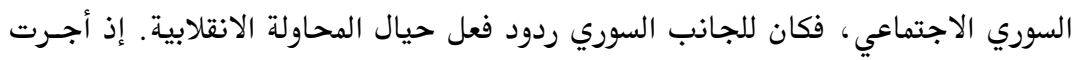

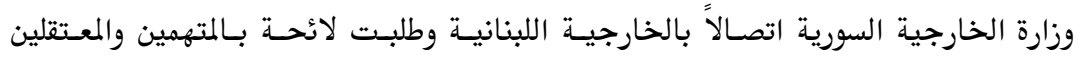
السوريين الضالعين في الانقلاب(39).

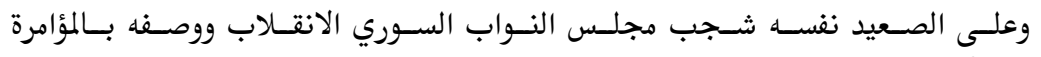

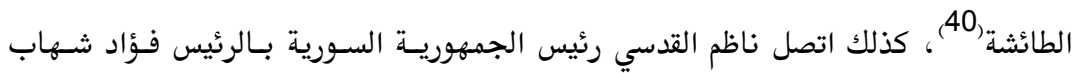

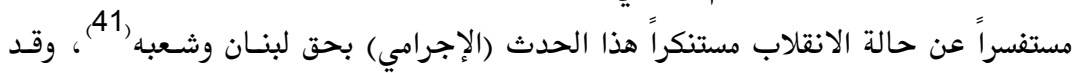
أطلعه فؤاد شهاب على آخر التطورات مطمأن إياه على سير الأمور وشاكراً له اهتمامه (42.

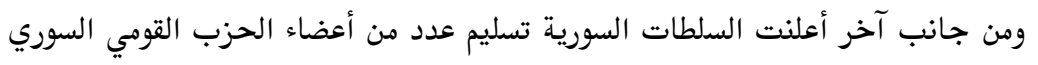

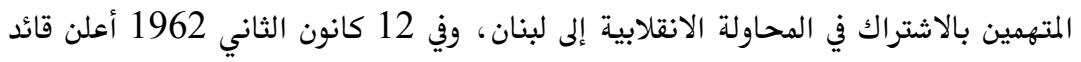

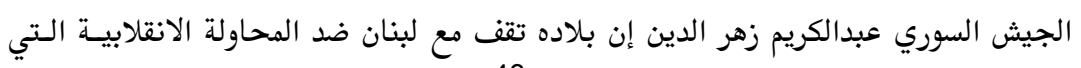

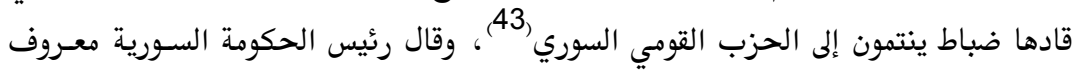

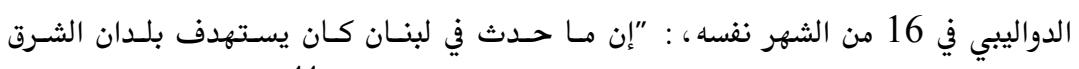

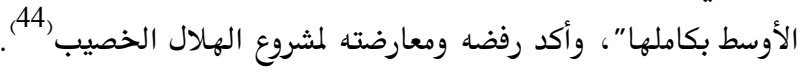

- توتر العلاقات بين البلدين خلال المدة (كانون الثاني 1962- آذار 1963) 


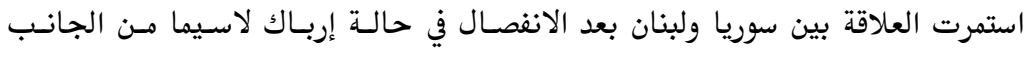

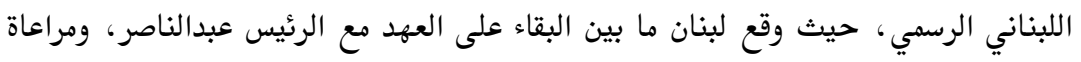

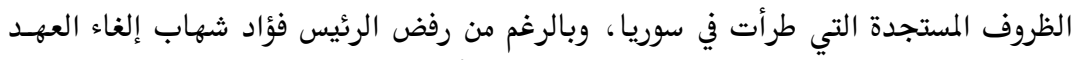

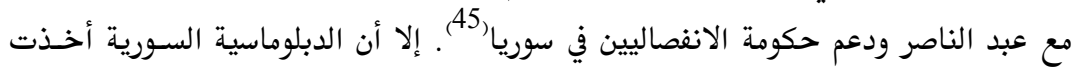

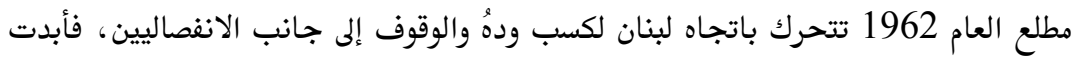

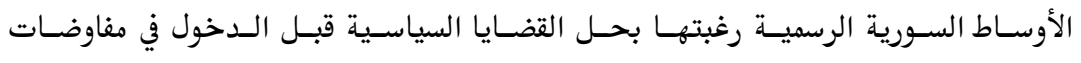

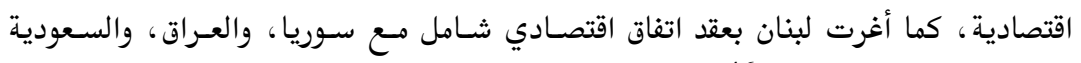

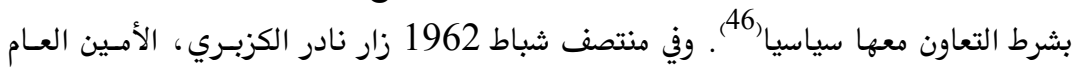

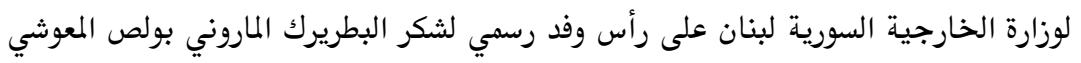

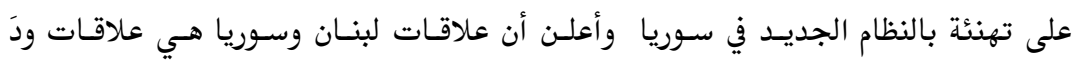

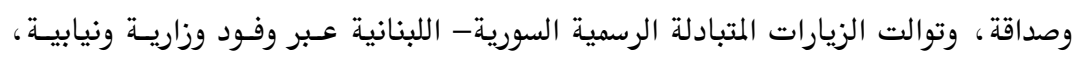

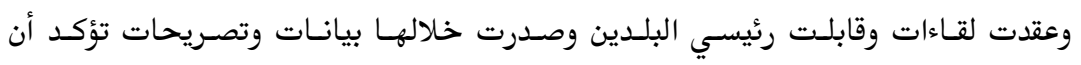

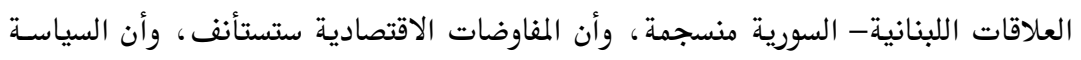
السورية تتلخص بإعادة المياه إلى مجاريها مع لبنان(

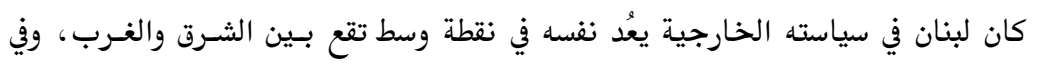

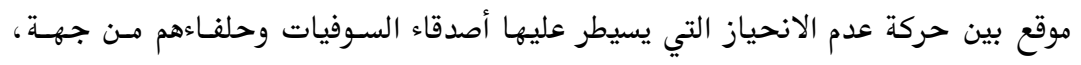

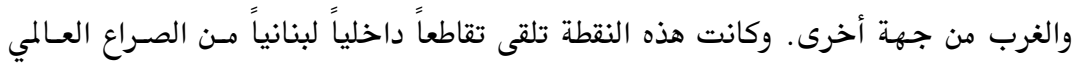
والحرب الباردة بين كتلتي القوتين الكبريين وكان التوافق الرسمي الخـارجي اللبنـاني أكثر التهر

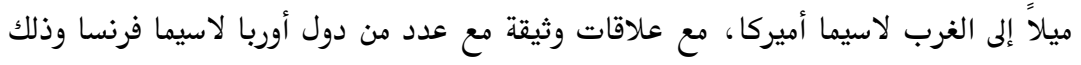

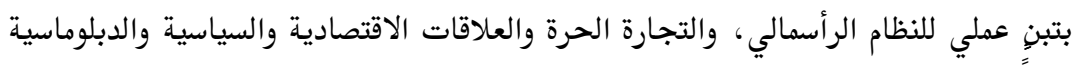

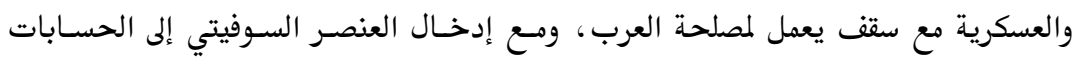

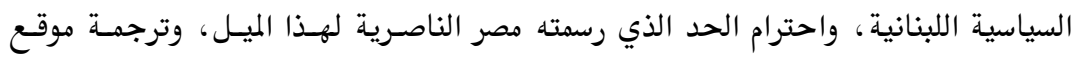

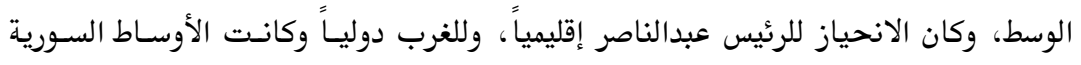

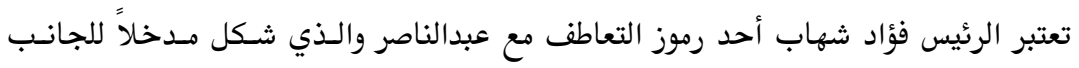


المصري لمساعدة الرئيس اللبناني في تهدئة المسلمين وانسجاههم هـع تطلعـات العهـد بينمـا

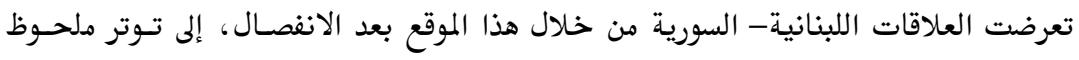

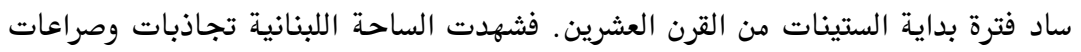

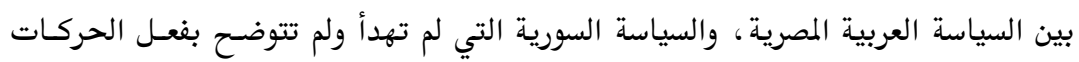
الانقلابية التي انسحبت في رجال السياسة والقادة لهذا البلد لهـئ. وساءت العلاقات بين سوريا ولبنان بسبب حملات الصحف اللبنانية في 30 أيار 1962

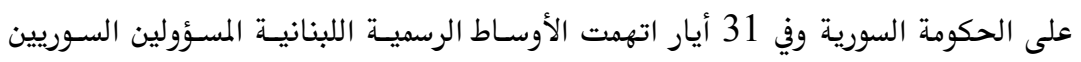

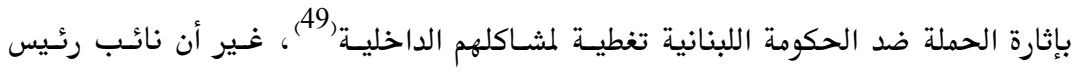

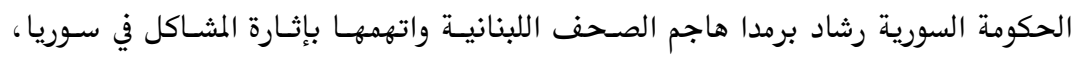

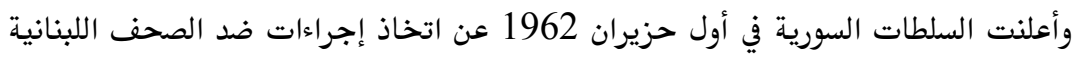
التي تهاجم سوريا وأرسل الـرئيس السـوري نـاظم القدسي رسـالة شـفوية إلى الـرئيس فؤئاد

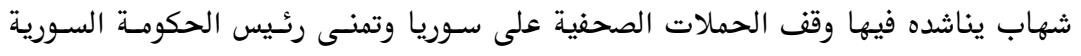

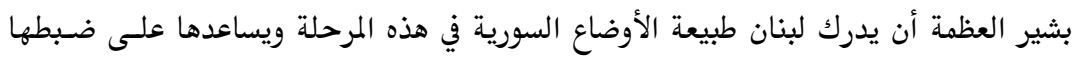

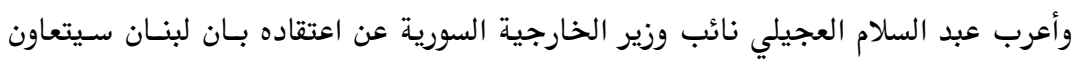

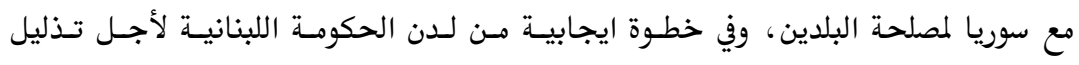

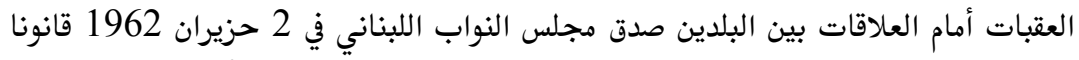
يجيز للحكومة اللبنانية ملاحقة الصحف التي تسيء إلى رؤساء الددول

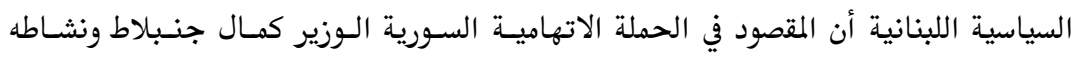

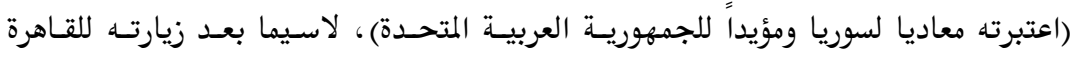

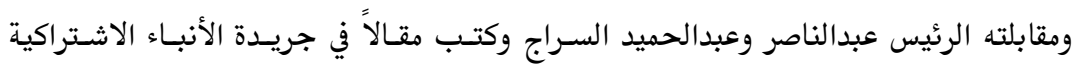

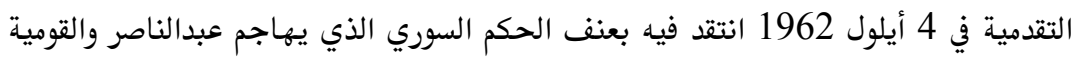

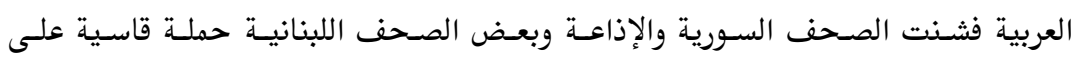

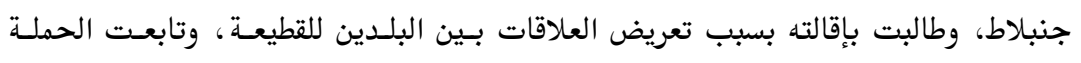

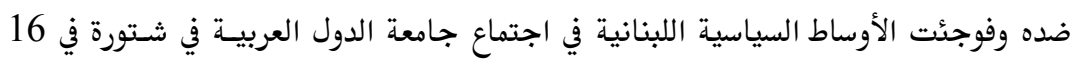

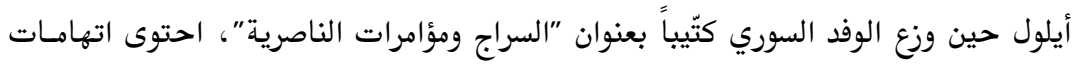


وافتراءات على عدد من الشخصيات اللبنانية (رشيد كرامي ورينيه معسوض وعـدنان الحكيم

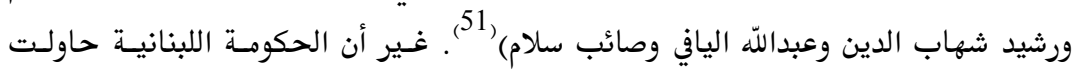

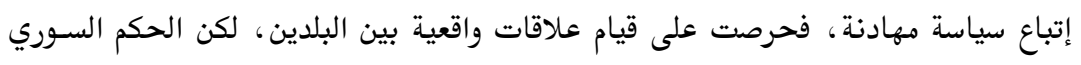

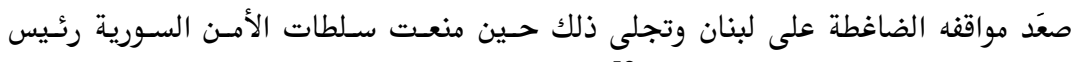

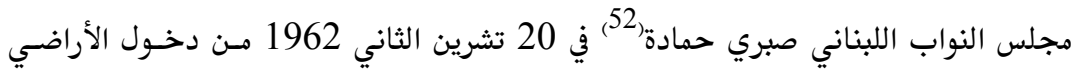

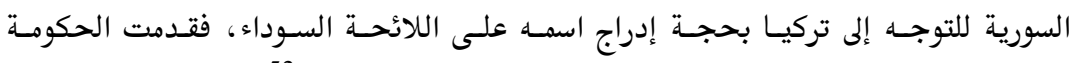

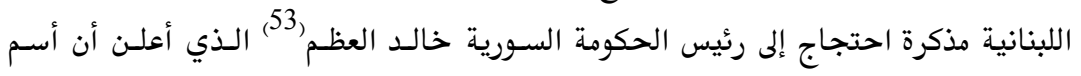

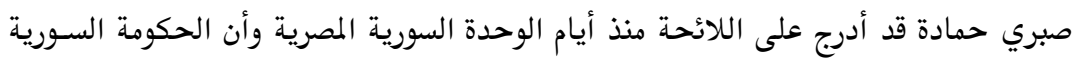

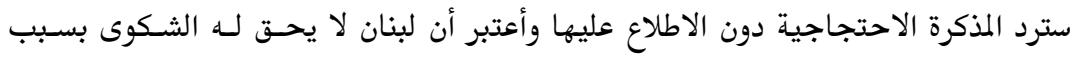

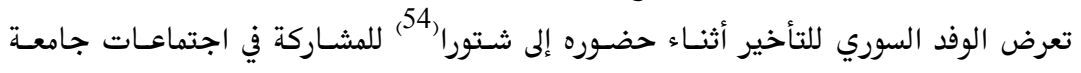
الدول العربية(55). وفي 28 تشرين الثاني 1962 علق النائب كاظم الصلح العضو في لجنة الشؤون الخارجية

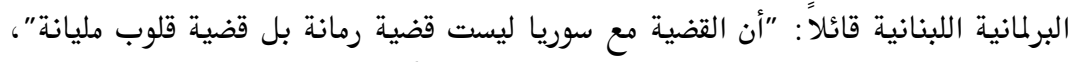

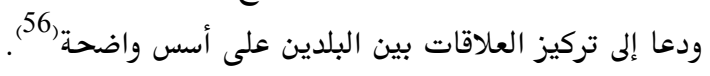

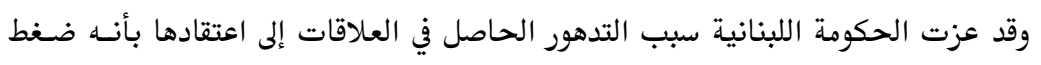

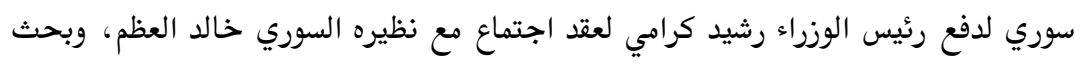

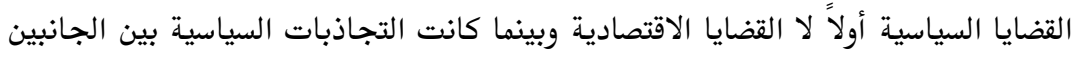

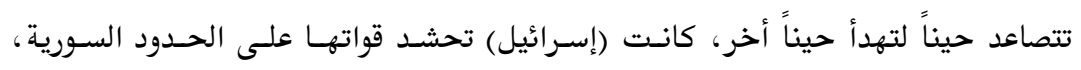

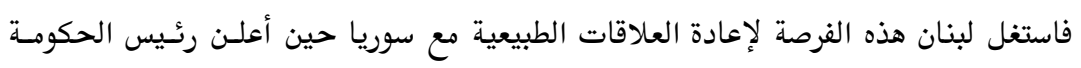

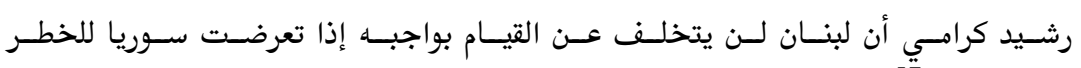

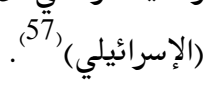
وفي جانب آخر، عدّتْ مصادر الحكم اللبناني أنسه لـن يكسون هنـاك اتصـال بـين لبنـان

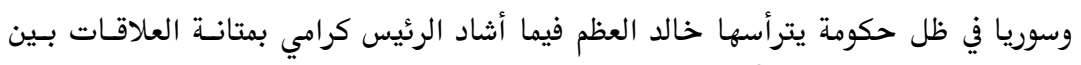
الشعبين اللبناني والسوري(58). 
ومع بداية العام 1963 تأزمت العلاقات بين البلدين بعد أن تعرضت منطقة دير العشائر

في قضاء راشيا بمحافظة البقاع إلى اعتـداء مسن قبـل القوات السـورية الـتي عـبرت الحسدود اللبنانية، وأسفر الاعتداء عن جرح العديد مسن الأشـخاص، وطالـب أهـل المنطقـة الحكومسة اللبنانية باتخاذ إجراءات لازمة لحمايتهم هناك، وعلىى اثر ذلك استنكر مجلس النـواب اللبناني المواقف التي وصفوها بـ (( العدوانية )) المتعددة التي يقوم بها الجيش السوري تجــاه لبنان، وهاجم النائب فريد جبران الحكومة السورية متهما المسؤولين في دمشق بـ (الرجعيين )، إلا أن وزير الخارجية اللبناني فيليب تقلا طلب عدم التهجم وإلقاء مثل هذه التهم على لـى دولة شقيقة وجارة للبنان(59).

\section{تطور العلاقات اللبنانية - السورية حتى نهاية حكم فؤاد شهاب - موقف لبنان من ثورة آذار 1963}

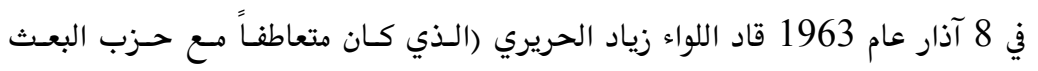

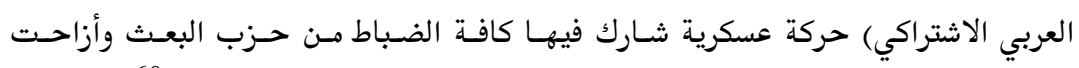

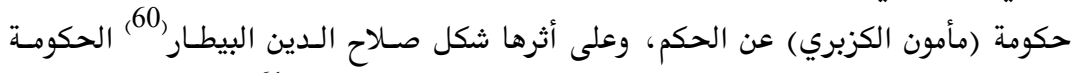
الجديدة واختير لؤي الأتاسي رئيساً للمجلس الوطني لقيـادة الثـورة) الحكومة اللبنانية أخبار ثورة 8 آذار 1963 فأعرب رئيس الحكومة رشيد كرامي عن تمنياته بأن ((تجتاز سوريا المرحلة التي تمر بها بما يتفق ومصلحة شعبها )) وأضاف (أن لبنان يتمنى الخير لكل دولة عربية تختار الذظام الذي يلائمها )، ورحب بالانقلاب وتمنى لشعب سـوريا

$$
\text { وجيشها القوة والازدهار(62). }
$$

كما عبرت الأحزاب اللبنانية عن مواقفها من ثورة آذار حسب توجهاتهـا السياسـية ، إذ أكسد كمـال جنـبلاط ببرقيـة أرسـلها إلى دمشـق عـبر فيهـا عـن موقـف الحـزب التقـدمي الاشتراكي، وجاء فيها : (ركانت انتفاضتكم تجسيداً لإرادة الشعب العربي في كل مكان، لقـد

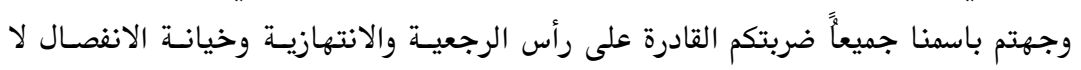
تتصوروا تأثير شعب لبنـان العميـق وفرحتـه في تتبـع أخبـار انطلاقـتكم الباسـلة إن في قـوة

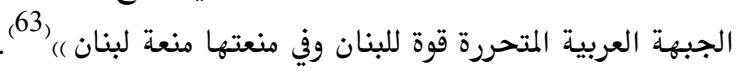




\section{- موقف لبنان من الوحدة الثلاثية}

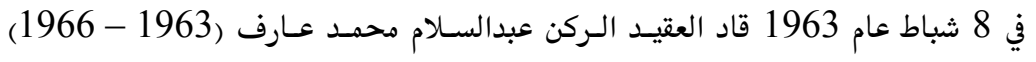
انقلابا في العراق ضد الرئيس العراقي الزعيم الركن عبدالكريم قاسم (1958 - 1963 196د) وبعديد

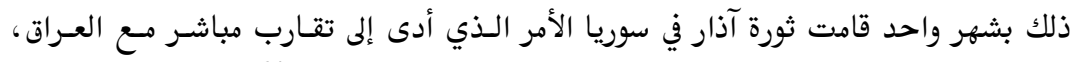

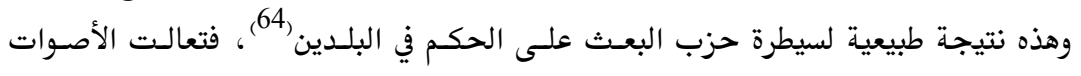

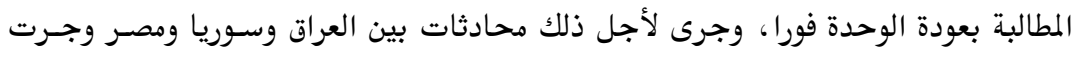

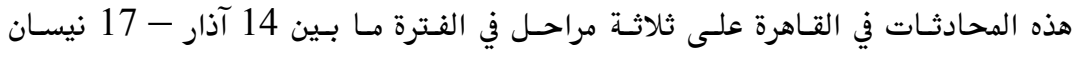
${ }^{65} 1963$

وخلال فترة محادثات هذه الوحدة الثلاثية رحب رئيس الحكومة اللبنانية بالاتفاق ، كما

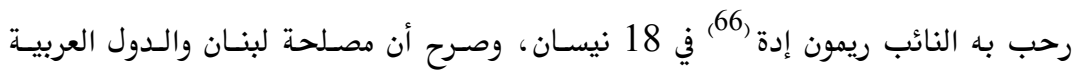

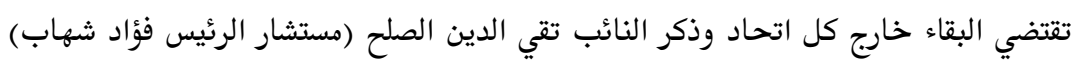

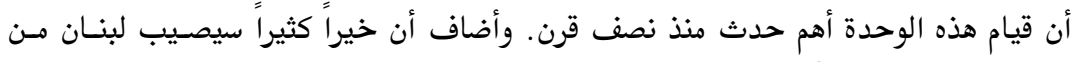
قيام الوحدة الثلاثية(67). وتوالت ردود الفعل في لبنان، فوجه الرئيس فؤاد شهاب برقيـة تهنئسة إلى رؤسـاء مصر

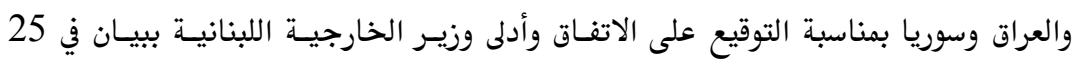

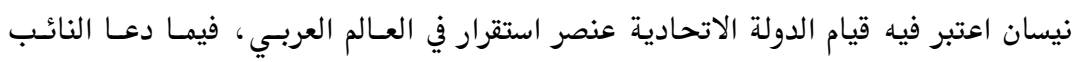

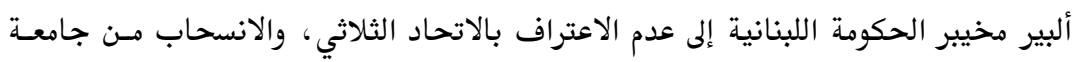

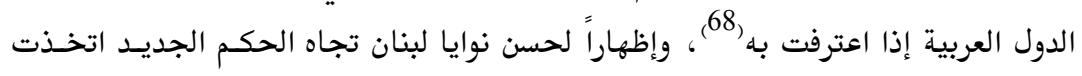

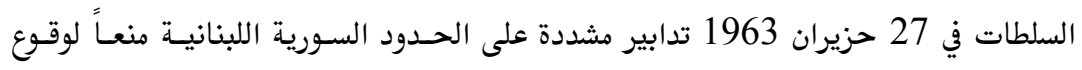

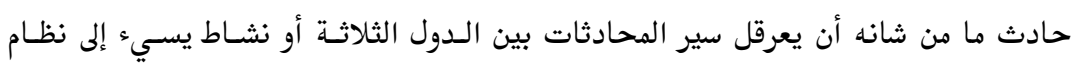

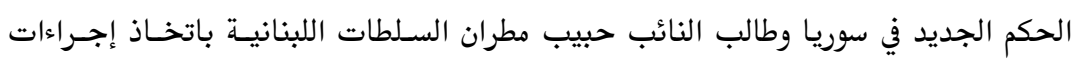

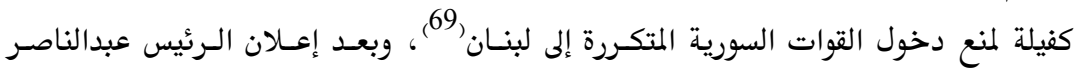

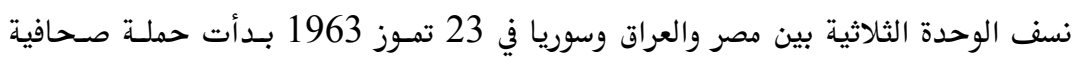


بين القاهرة من جهة، ودمشق وبغداد من جهة ثانية. شاركت فيها الصحف اللبنانية ما بين

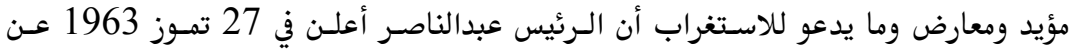

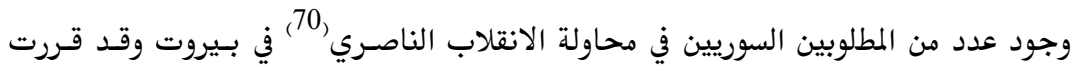

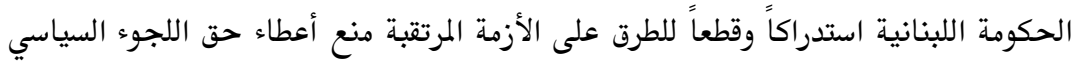

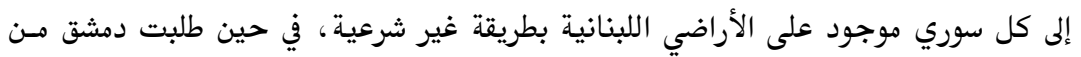
بيروت إجراءات لوقف هذه الحملات حفاظاً على مصلحة البلدين الشقيقين(71).

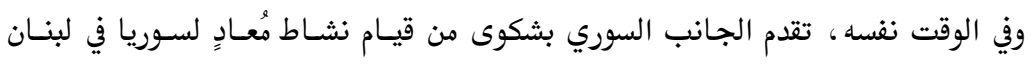

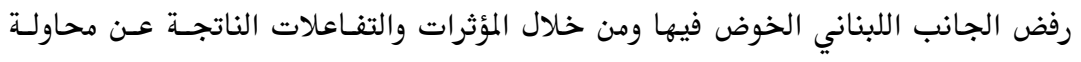

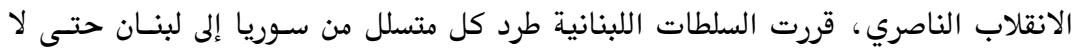

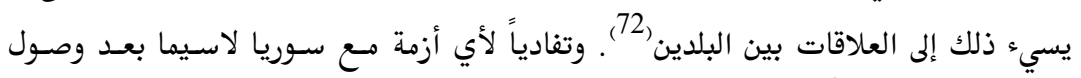

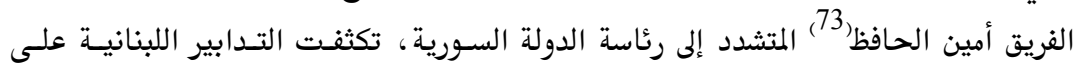
الحدود اللبنانية- السورية، ونفى لبنــان توسطه لإنقـاذ المـتهمين بمحاولـة الانقـلاب(74).

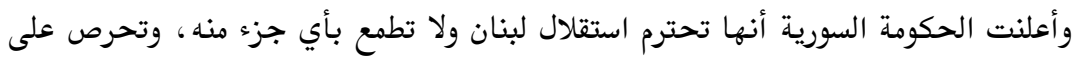

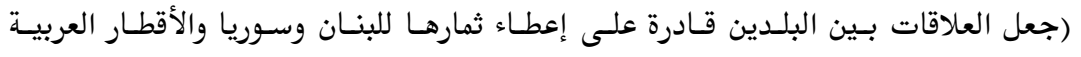

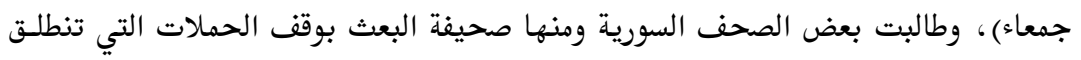

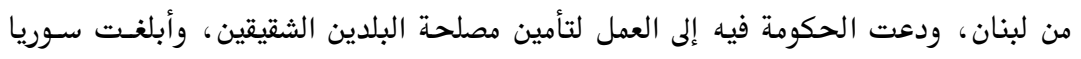

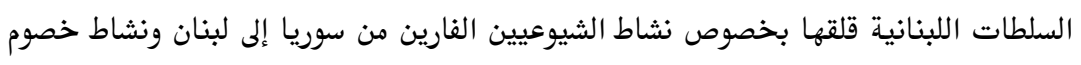

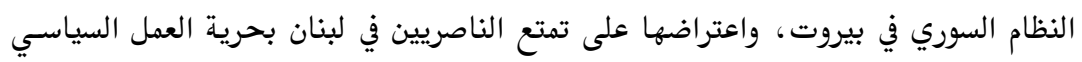

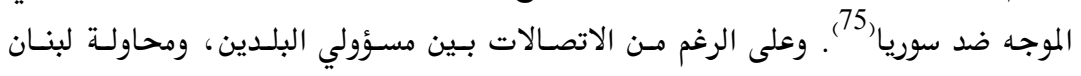
إظهار موقفه الحيادي من الصراع الناصري- البعثي (لقاء الزعيم يوسف شميط رئي رئيس الأركان

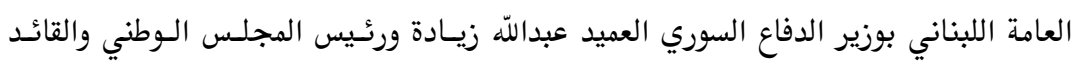

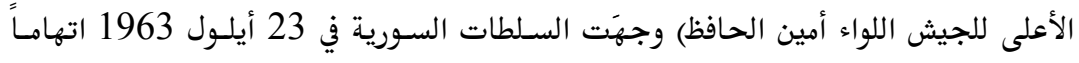

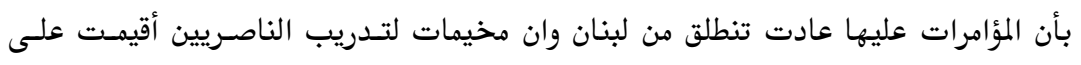

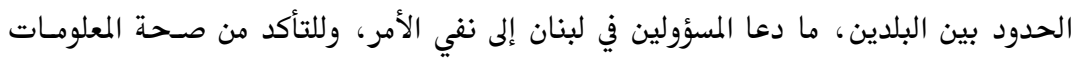

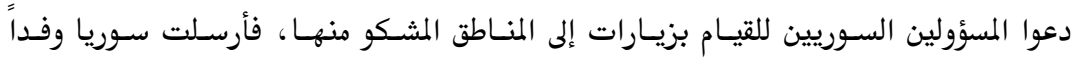




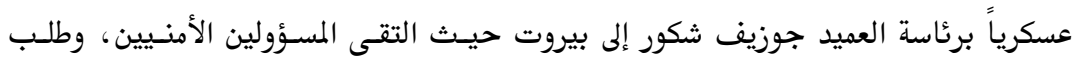

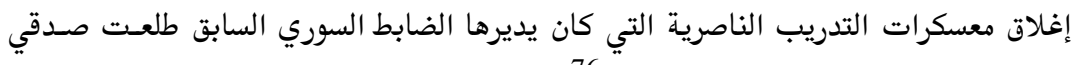

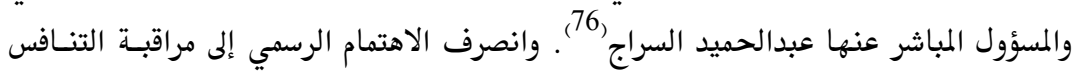

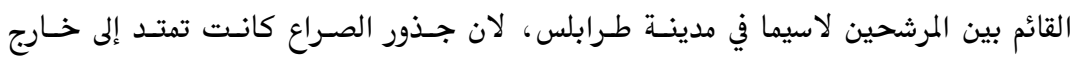

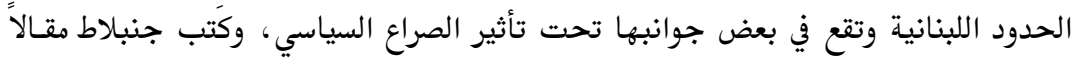

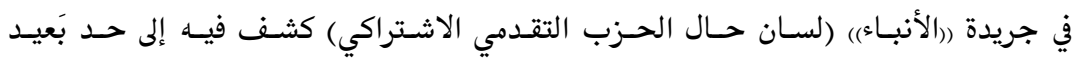

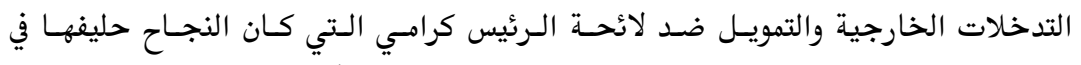

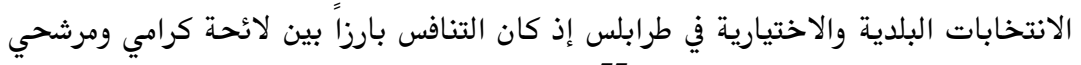
حزب البعث الحاكم في سوريا والعراق(77). استمر توتر العلاقات اللبنانية- السورية رغم تعهد السلطات اللبنانيـة بتسليم السـوريين الذين يتم القبض عليهم إلى حكومتهم ووجهت السلطات السورية في 8 تشرين الأول 1963

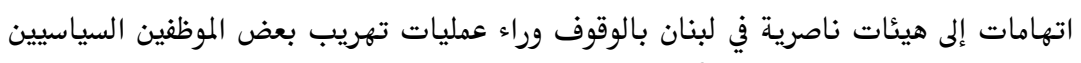

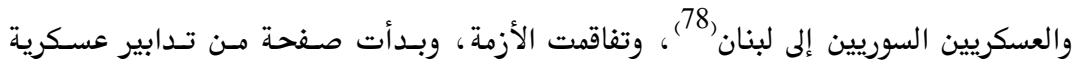

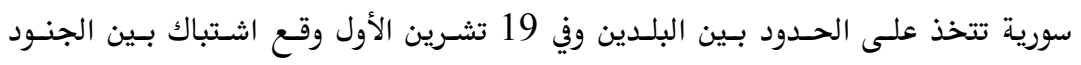

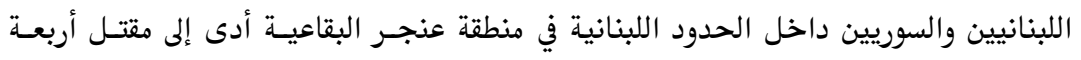

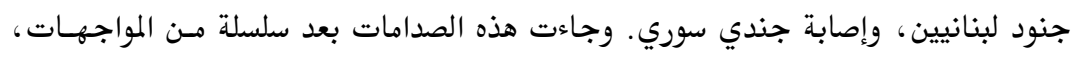

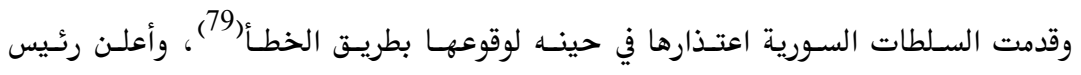

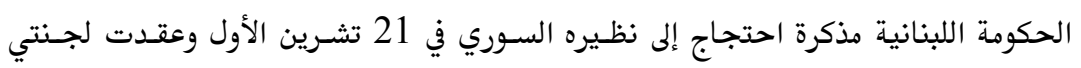

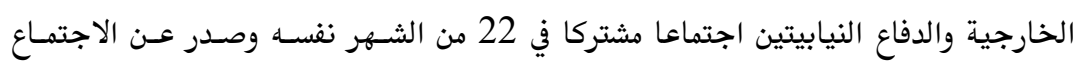
بيانا ناقش فيه الاعتداء السوري على الأراضي اللبنانية وأسبابه وظروفه والنتائج السيئة التي لئي

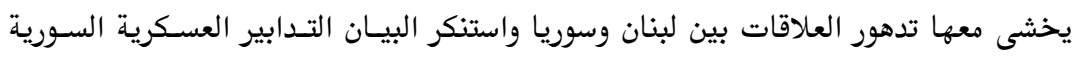

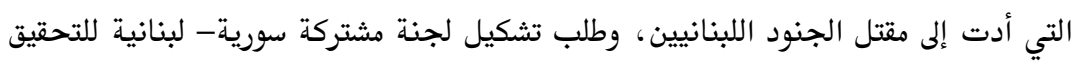


من جانبه أدلى رئيس الوزراء اللبناني بكلمة أعرب فيها عن ألمه الشـديد لهـذا الحسادث

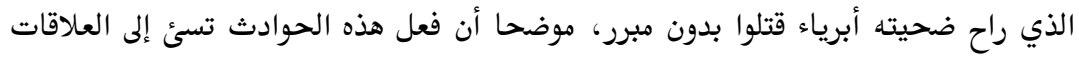

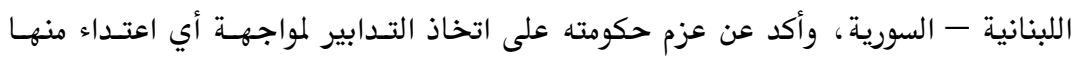

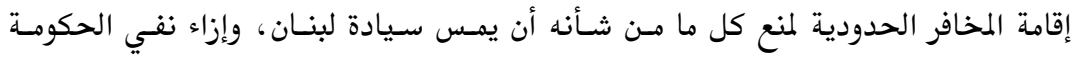

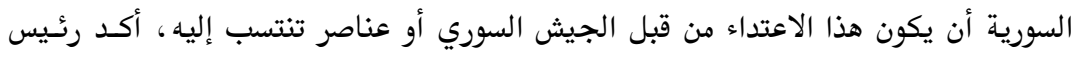

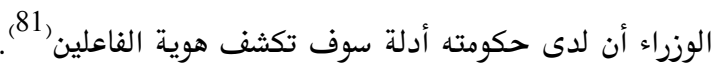

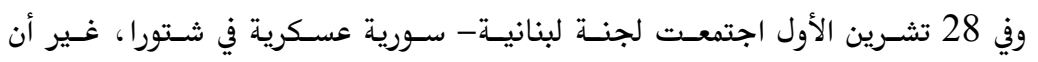

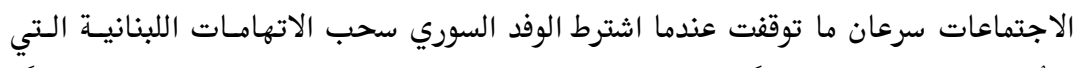

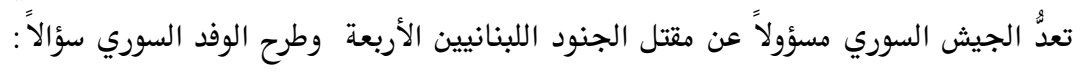

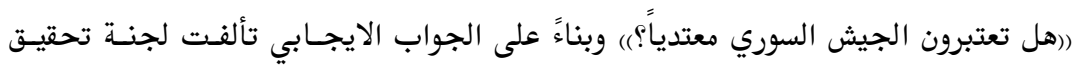

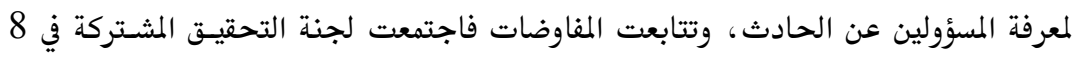

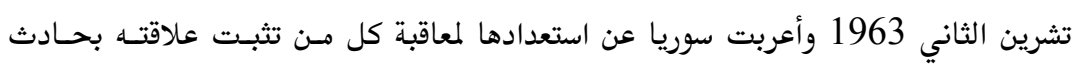

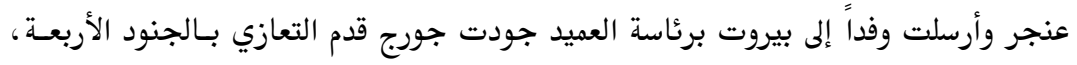
كما قدم مبلغ (50) ألف ليرة تدفع لذوي الشهداء، فيما أطلقت السلطات العسكرية اللبنانية

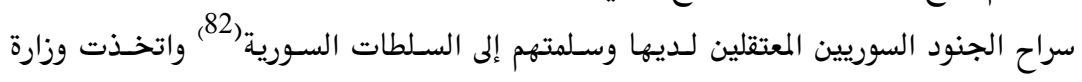

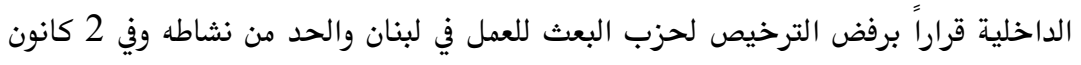

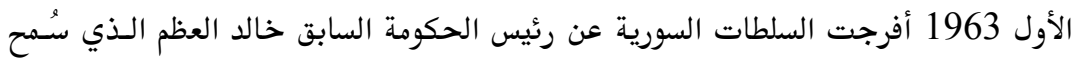

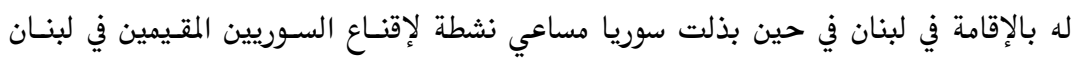

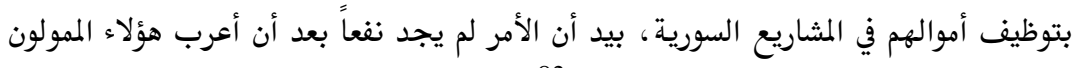

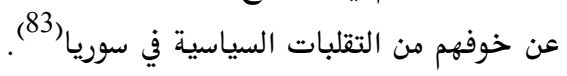

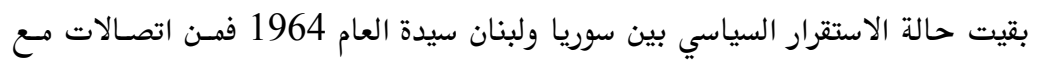

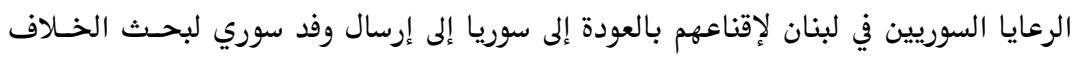

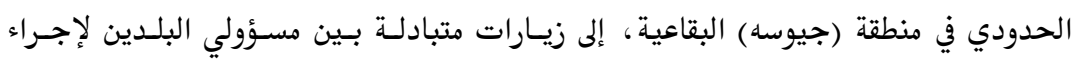

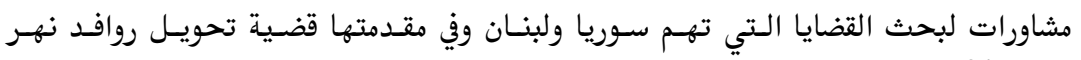

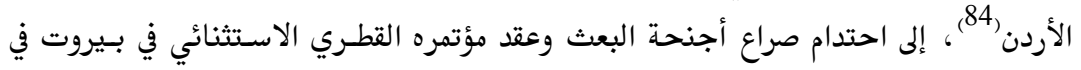


21 شباط 1964 لبحث الخلافات داخل صفوف الحزب، واعتبار أمينهُ العام ميشيل عفلق

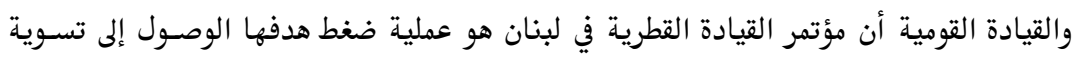

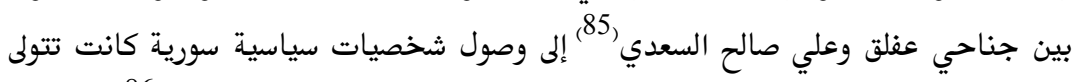

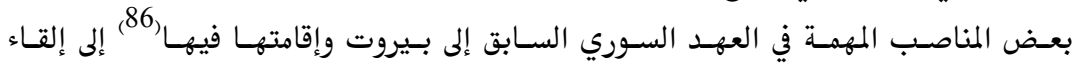

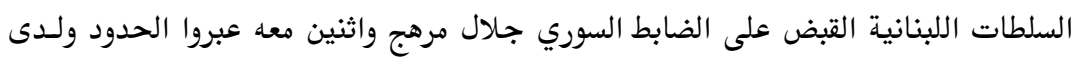

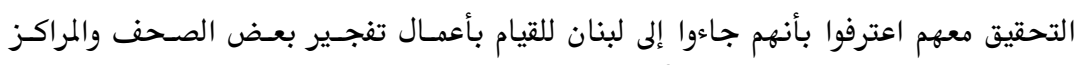

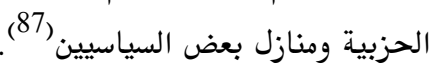

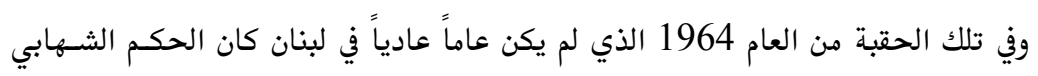

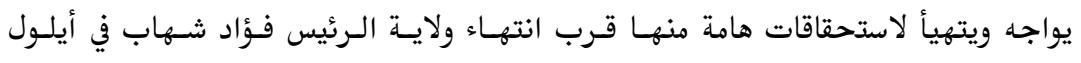
وانتخاب رئيس جديد للبلاد.

الخاتمة اتسمت العلاقات اللبنانية السورية بالتأرجح من وقت لآخر بـين التطسور والنمسو والفتـور

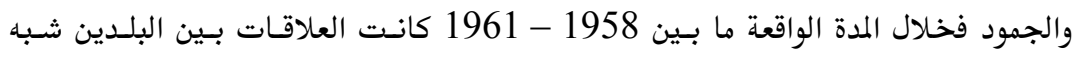

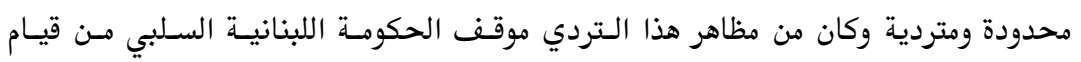

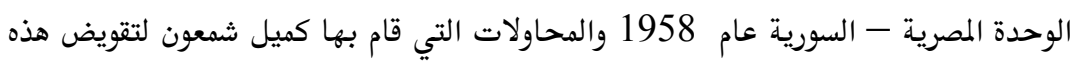
الوحدة.

وبعد تولي اللواء فؤاد شهاب منصب رئاسة الجمهورية اللبنانية برز تطور جديد لسياسة

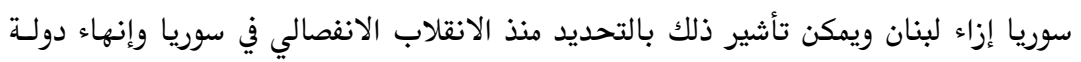

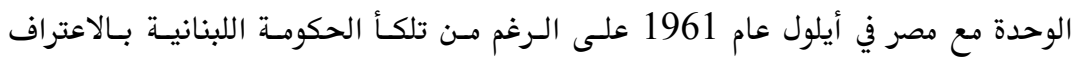
بالحكم الجديد. وبعد ثورة آذار في سوريا عام 1963 أخــت العلاقـات اللبنانيـة السـورية تسـير في طريـق

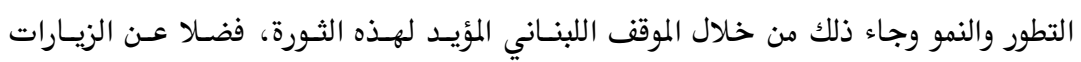




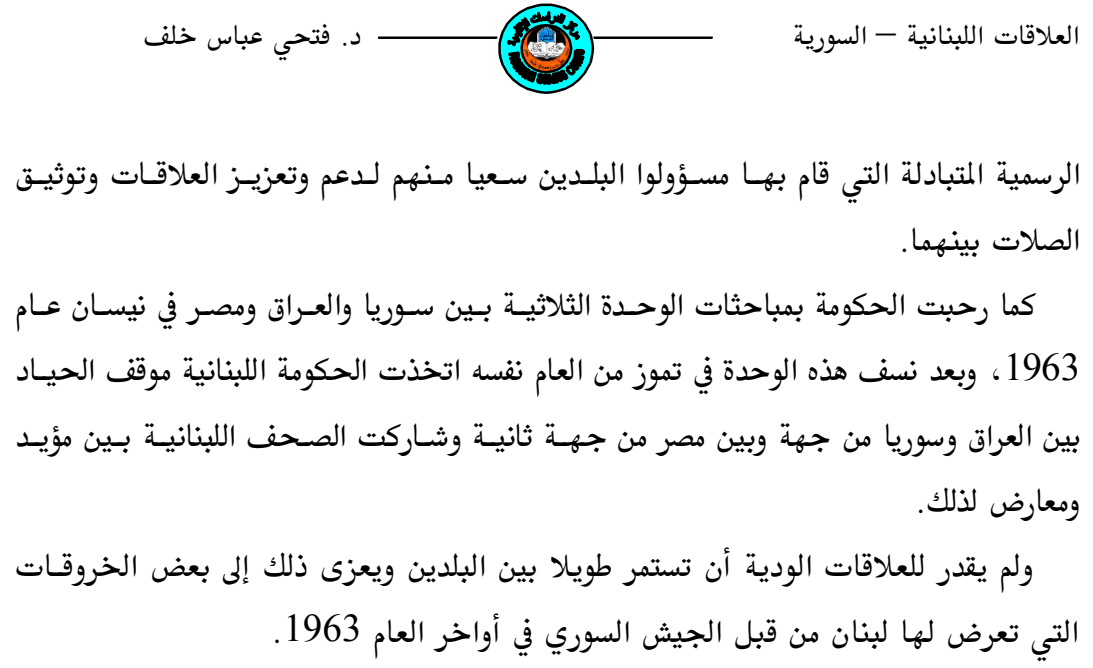

\title{
The Lebanon - Syrian Relations1961 - 1964
}

Dr. Fathi A. Khalal

lectures/Callege of Education/Department of History

I University of Mosul

\begin{abstract}
This research tackled with a very important period of the political history of Lebanon and Syria (1961-1964), which lay between the broke away of the United Arab Republic, and what followed this broke away at the formal and informal level, by the end of the role of the Lebanon president fo'ad Shihab in 1964.

The research deals with a very important era, for this reason Syria began to gain Lebanon side after the secession from Egypt, to overcome the Nazarene currents in the region.
\end{abstract}




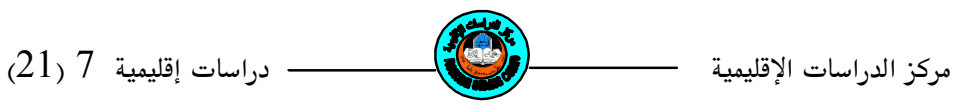

This research is divided into an introduction and two section, the introduction gives a historical background before 1961. Section One spoke about the relation between Lebanon and Syria after the disengagement، till the Syrian revaluation in 1963.

Section two deals with the developments of bilateral relations between Lebanon and Syria until the end of the role of the president Fo'ad Shihab in 1964.

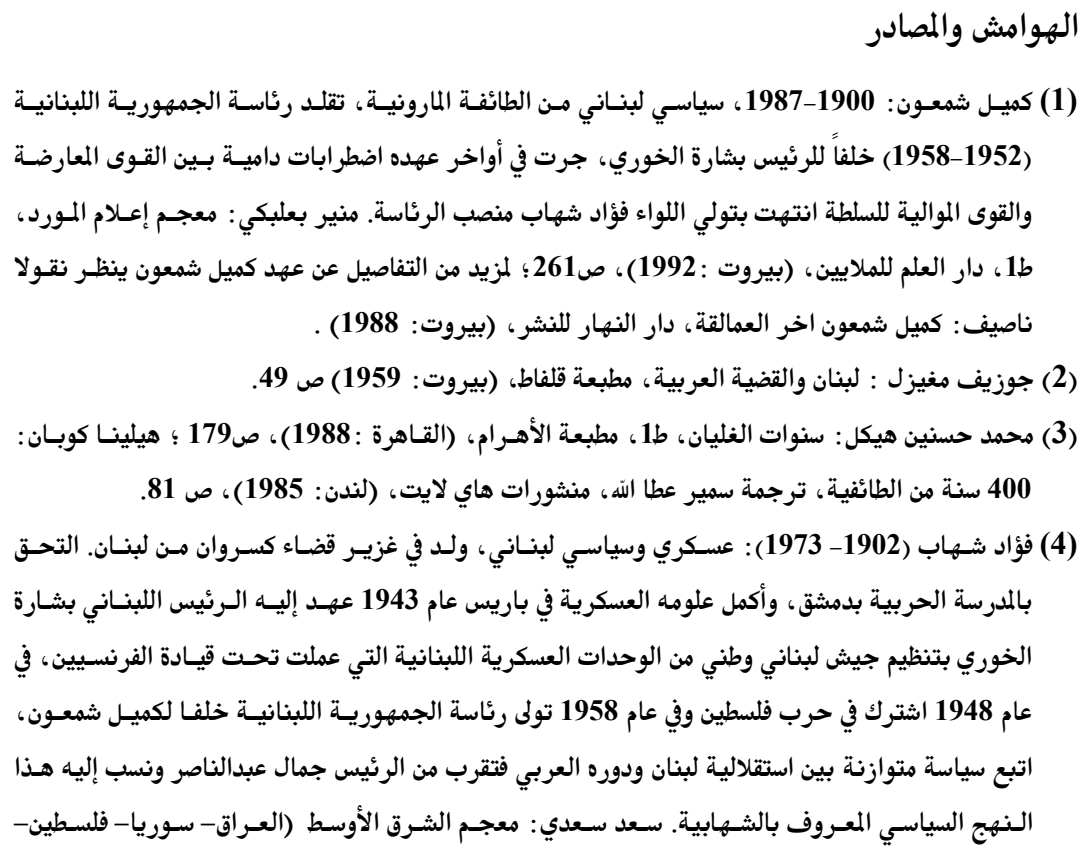




$$
\begin{aligned}
& \text { د. فتحي عباس خلف } \\
& \text { (2) } \\
& \text { العلاقات اللبنانية - السورية }
\end{aligned}
$$

John Entelis, pluralism and party transformation in Lebanon AL- Kataib 1936 1970, (Beirut :1974).

(10) الحزب القومي السوري الاجتماعي: تأسس في بيروت عام 1932 على يد أنطوان سعادة ومجموعـة مـن الطـلاب

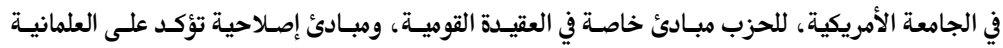

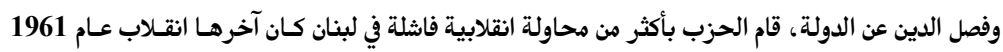

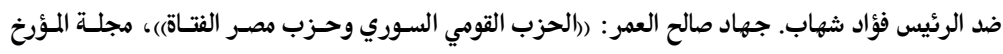

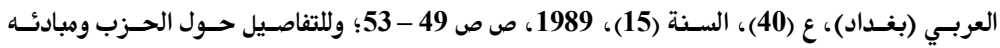
وأفكاره راجع:

Michal W. Suleiman :Political Parties in Lebanon, The challenge of Afragmented political culture, first Publicated, Cornell university press, ( New York : 1976), p.19.

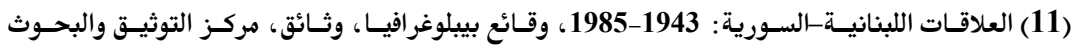

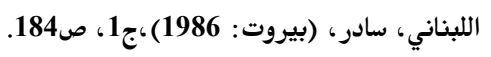

(12) في يوم 4 تموز 1959 اعتقلته السـلطات السـورية في احسد شـوارع دمشتق وسط اجـواء مشحونة في سـوريا،

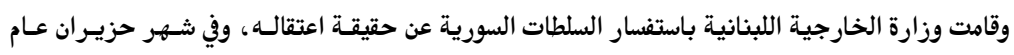

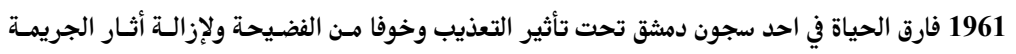

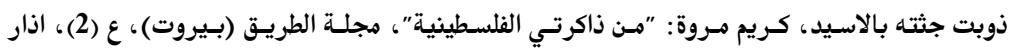


(13) جريدة النهار (اللبنانية)، 6 شباط، 1961.

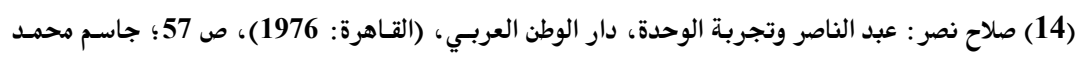

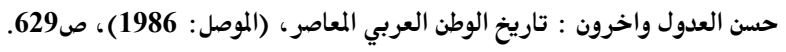

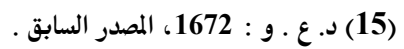

(16) نبيل خليفة، الستراتجيات السورية والإسرائيلية والأوربية حيال لبنان، بحث في مصير الدولة_الحـاجز،

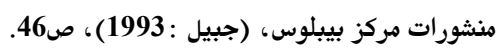

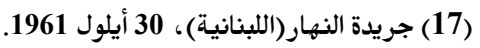

1961 ..From Cario to October 5،Foreign office 371/1578251/88025 -18

(19) جريدة النهار(اللبنانية)، 30 أيلول 1961.

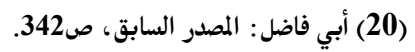

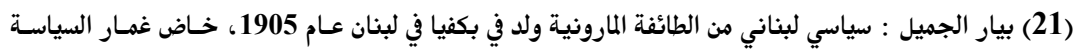

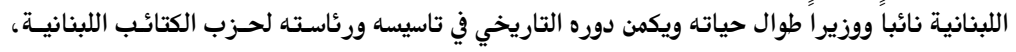

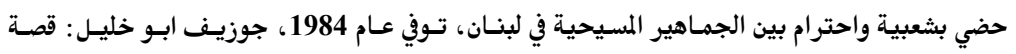

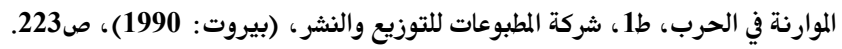

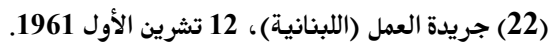

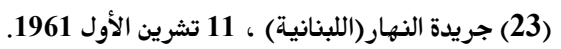

(24) الحزب التقدمي الاشتراكي: حزب سياسي اسسه كمال جنبلاط في آذار عام 1949، معظم أنصاره مسن طائفـة

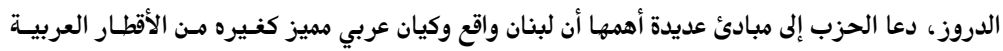
ودولة مستقلة، لعب دورا في الحيـاة السياسية اللبنانيسة، وقـف موقف المعـارض لحكـم بشـارة الخـوري

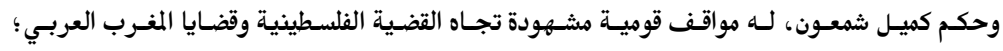
( P.P ، Suleiman :OP .CIT

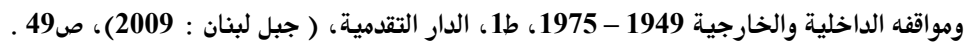

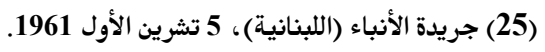

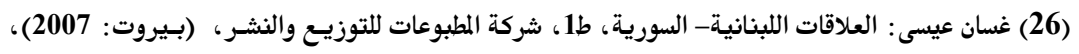

ص ص 517-518.

(27) نشأت هذه الحركة في أوائل الخمسينيات من القرن المنصرم في الجامعة الأمريكية في بـيروت، أسسها طلبـة

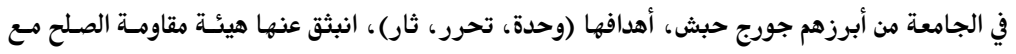

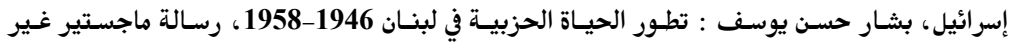

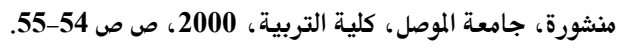


د. فتحي عباس خلف

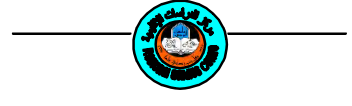

(28) عيسى : المصدر السابق، ص518.

(29) جريدة النهار (اللبنانية)، 11 تشرين الأول 1961.

(30) العلاقات اللبنانية - السورية، ص ص 196 - 197 ـ 196 ( 150

(32) جريدة النهار( اللبنانية )، 15 تشرين الأول 1961 . 1961 .

(32) جريدة الأنوار (اللبنانية)، 20 تشرين الأول 1961 ـ

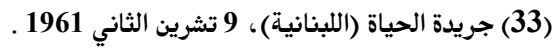

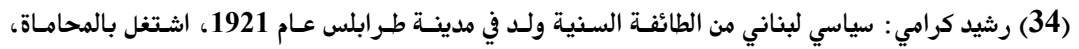

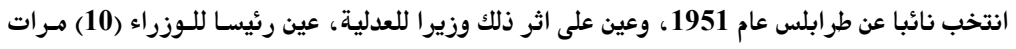
خلال الأعوام 1955 و 1958 (مرتين) و 1961 و 1965 و 1966 و 1969 (مـرتين) و 1965 و 1975 وآخرهـا في عين

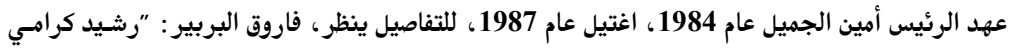

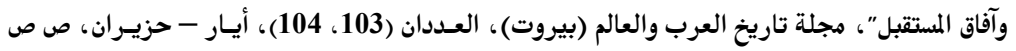

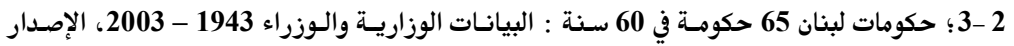
الرابع، جمع وتقديم جان ملحة، ط1، مكتبة لبنان ناشرون، (بيروت:

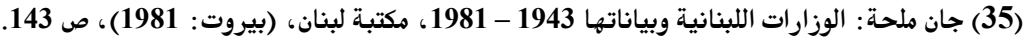

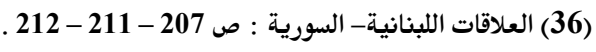
(37) كمال جنبلاط (1917-1977): سياسي لبناني من أسرة درزية عريقـة قدمت إلى لبنـان عـام 1630 بـدعوة

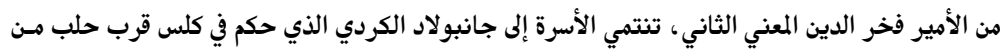

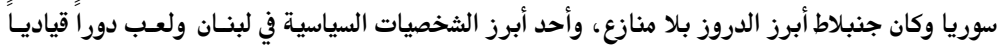

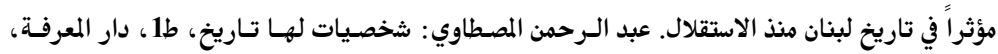

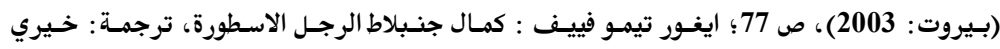

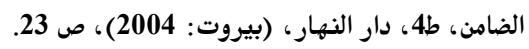

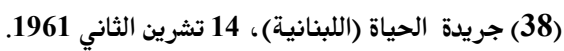

$$
\text { (39) عيسى: المصدر السابق، ص } 529 .
$$

(40) جريدة المستقبل (العراقية)، 343 في 4 كانون الثاني 1962؛ جريدة صوت الأحرار (العراقيسة)، 982 في

4 كانون الثاني 1962.

(41) جريدة المستقبل (العراقية) 342 في 4 كانون الثاني 1962 ـاندي

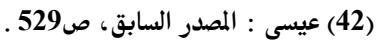

(43) جريدة المستقبل (العراقية)، 343 في 4 كانون الثاني 1962؛ جريدة صسوت الأحسرار (العراقيسة)، 982 في

4 كانون الثاني 1962. 
(44) الهلال الخصيب : مشروع اقترحه نوري السعيد رئيس وزراء العراق عام 1942 وذلك في مذكرة قدمها إلى

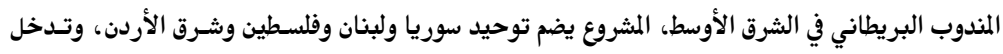

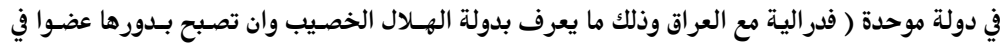

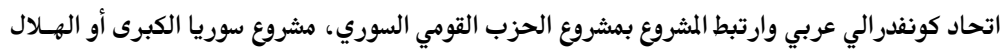

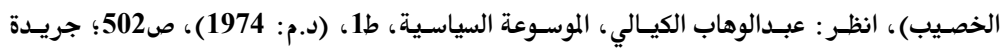

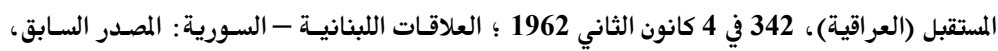
(45) مائير زامير، نشوء لبنان الحديث، ترجمة دار المروج، (بيروت: 1986) ص165.

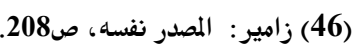

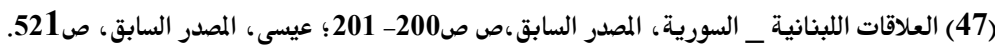

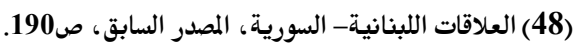
(49) جريدة التلغراف (اللبنانية)، 30، 31 أيار 1962.

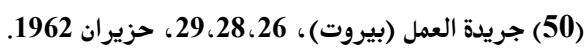
(51) عيسى: المصدر السابق، ص203. (503.

(52) صبري حمادة: سياسي لبناني من الطائفـة الشيعية، ولـد في مدينـة بعلبـك، تـولى رئاسـة مجلـس النـواب

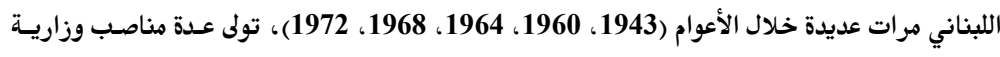

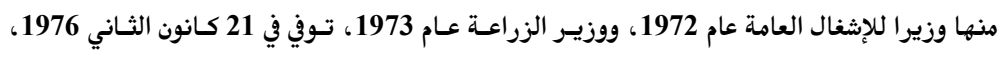

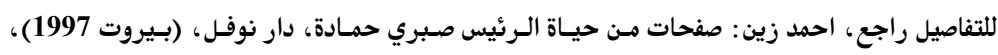
ص13. (53) خالد العظم: ولد في دمشق عام 1903، دخل السياسة عام 1941 لترأس الحكومة السورية، وشغل العديـد

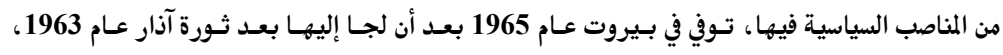

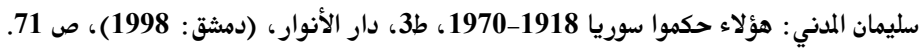

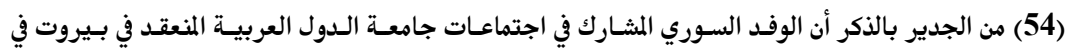
تشرين الأول 1962 كان قد تعرض إلى التأخير على الحدود اللبنانية - السورية. (55) جريدة الحياة، (اللبنانية)، 27 تشرين الثاني 1962.

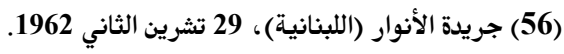

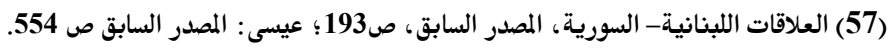
(58) جريدة النهار (اللبنانية)، 20 كانون الأول 1962. 
د. فتحي عباس خلف

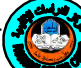

العلاقات اللبنانية - السورية

(59) محاضر مجلس النواب اللبناني، الدور التشريعي العاشر، العقد الاستثنائي الثـاني، الجلسـة (1) المنعقدة

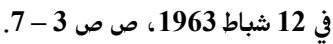

(60) صلاح الدين البيطار (1912 - 1980): سياسي سوري، تولى عـدة مناصب في الحكومـات المتعاقبــة ومنهـا

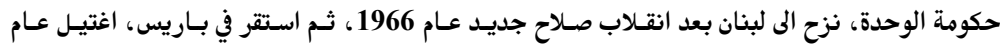

1980، سعدي: المصدر السابق، ص 90.

(61) اسـعد الكـوراني: ذكريـات وخـواطر ممـا رأيـت وسمعـت وفعلتـ، ط1، ريـاض الـريس للكتب والنشـر،

(بيروت: 2000) ص ص 390 - 391، وللوقوف على أسباب الثورة والعناصر المسـاهمة فيهـا وأهـدافها

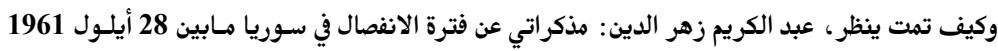

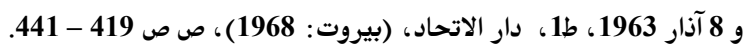

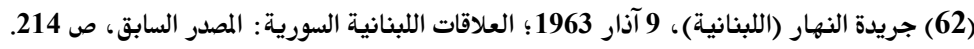

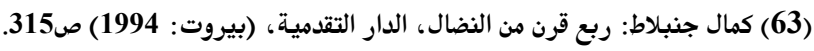

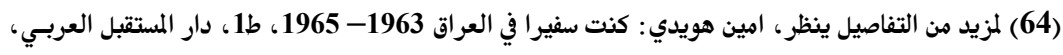

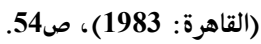

(65) قاسم سلام: البعث والوطن العربي، مذشورات العالم العربي، (باريس: د / ت)، ص ص 187.

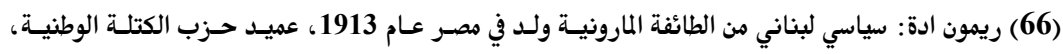

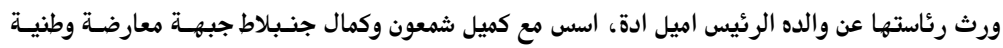

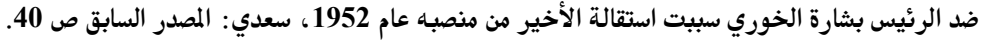

$$
\begin{aligned}
& \text { (67) جريدة الأنوار (بيروت)، } 19 \text { نيسان } 1963 . \\
& \text { (68) جريدة النهار(بيروت)، } 26 \text { نيسان } 1963 .
\end{aligned}
$$

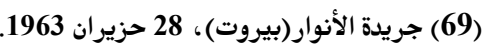

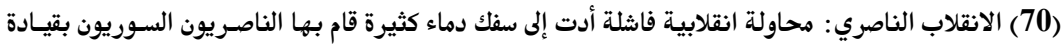

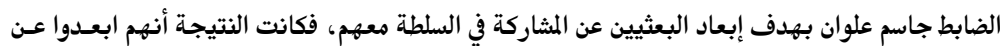

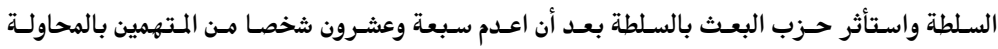

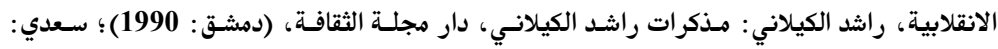

$$
\text { المصدر السابق، ص65. }
$$

(71) (71) عيسى: المصدر السابق، صل560.

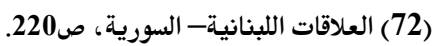

(73) امين الحافظ : رئيس الجمهورية العربية السورية بين 1963 و 1966، 1966، ولد في حلب عام 1921، 1921، في شباط

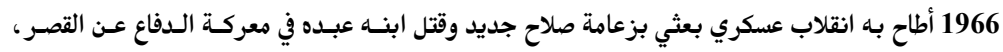

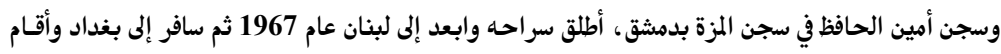




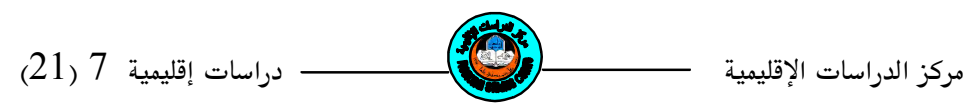

فيها تلبية لدعوى من الحكومة العراقية عام 1968، تمـام الـبرازي: ملفــات المعارضـة السـورية، مكتبـة مدبولي، (القاهرة: 1994)، ص 76 ؛

(74) جريدة النهار (بيروت)، 31 تموز 1963 (العاهره: 1963.

(75) العلاقات اللبنانية- السورية، المصدر السابق، صويدة (223؛؛ عيسى : المصدر السابق، ص 562.

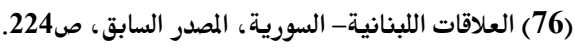

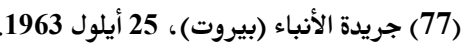

(78) جريدة النهار (بيروت)، 9 تشرين الأول 1963 (بيروت)، 195

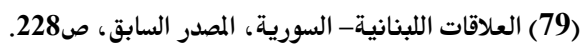

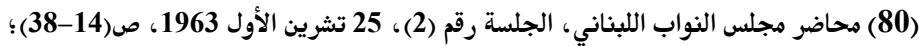

kamal Salibi, (" Lebanon under Fouad Chehab 1958 - 1964 ), Middle eastern Studies, (U . k ) Vol .2, 1966, p.p . 214 - 215.

(81) محاضر المجلس النيابي اللبناني، الدور التشريعي العاشر، العقد العادي الثـاني، الجلسـة (1) المنعقدة في 22 تثرين الثاني 1963.

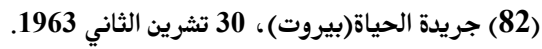

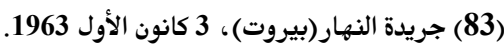

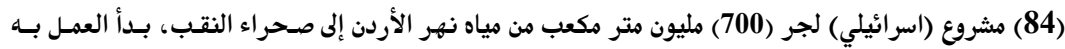

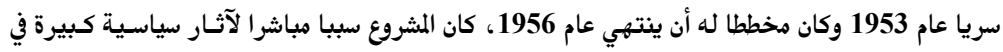

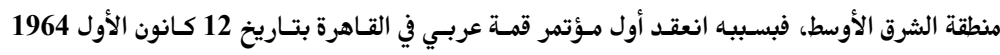

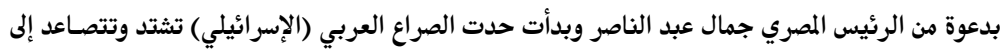

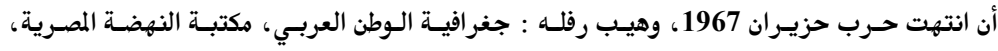

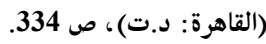
(85) هاني خليل : حافظ الأسد الإيديولوجية الثورية والفكر السياسي، طـلاس للدراسـات والترجمسة والنشـر،

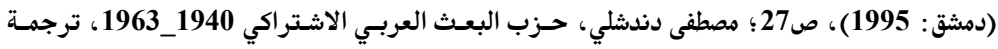

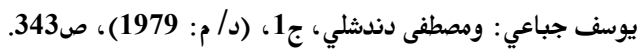

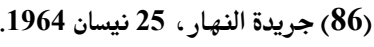
(87) جريدة النهار، 19 أيار 1964 (8) نوريدان. 